Portland State University

PDXScholar

1989

\title{
The physiology and biochemistry of isolated skeletal muscle mitochondria : a comparative study
}

Mark Lowell Wagner

Portland State University

Follow this and additional works at: https://pdxscholar.library.pdx.edu/open_access_etds

Part of the Biochemistry Commons, and the Physiology Commons Let us know how access to this document benefits you.

Recommended Citation

Wagner, Mark Lowell, "The physiology and biochemistry of isolated skeletal muscle mitochondria : a comparative study" (1989). Dissertations and Theses. Paper 3956.

https://doi.org/10.15760/etd.5842

This Thesis is brought to you for free and open access. It has been accepted for inclusion in Dissertations and Theses by an authorized administrator of PDXScholar. Please contact us if we can make this document more accessible: pdxscholar@pdx.edu. 
AN ABSTRACT OF THE THESIS OF Mark Lowell Wagner for the Master of Science in Biology presented March 27, 1989.

Title: The Physiology and Biochemistry of Isolated Skeletal Muscle Mitochondria: A Comparative Study.

APPROVED BY THE MEMBERS OF THE THESIS COMMITTEE:

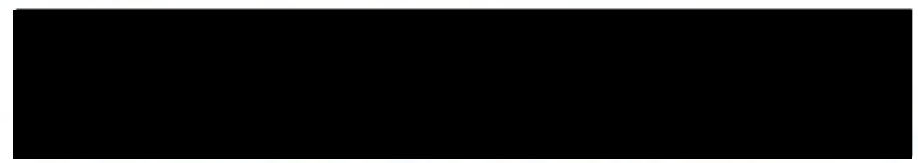

\section{Malcolm S. Lea, Chair}

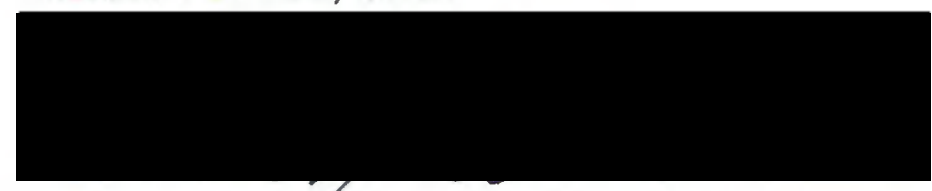

Stanley S. Hillman

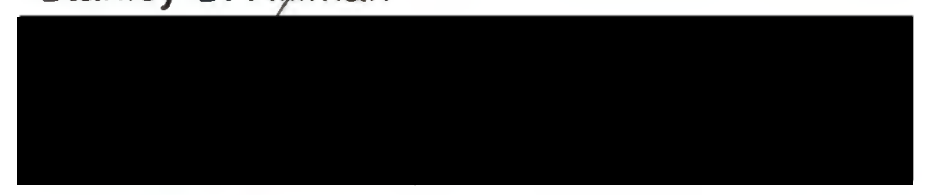

Richard B. Forbes

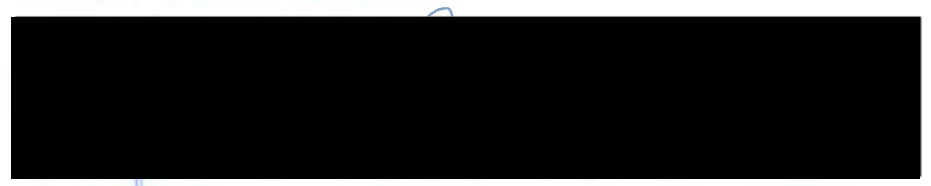

Alfred S. Levinson

The physiological limit to maximum aerobic capacity $\left(\mathrm{VO}_{2}\right.$ max $)$ in 
vertebrates has been attributed to cardiovascular oxygen delivery, to the ability of the muscle cells to consume oxygen, or to a fine-tuned development of all components of the respiratory system such that no single component can be shown to limit $\mathrm{VO}_{2} \max$. The above hypotheses have each been developed using different experiments with different animals. The comparative studies uniting these animals and methods are limited. In order to further our knowledge of the cellular limit to $\mathrm{VO}_{2}$ max, skeletal muscle mitochondria were isolated from species representing four vertebrate classes, and endothermic and ectothermic physiology. Mitochondrial $\mathrm{VO}_{2}$ was measured at 15,25 and $35^{\circ} \mathrm{C}$ and the results were compared between species and endothermic and ectothermic groups. Mitochondrial enzyme activities were measured at the three treatment temperatures to ascertain which enzyme activity best represents $\mathrm{VO}_{2}$ max for all vertebrates. Cytochrome difference spectra were measured to determine the concentrations of mitochondrial cytochromes $c+c_{1}$. The results show that mitochondria are unique in all species tested. Each species has its own response to changing temperature and its own mitochondrial enzyme activity profile. In addition, in vitro measurements of mitochondrial $\mathrm{VO}_{2}$ for all species show rates significantly higher than those estimated from whole organism measurements of 
$\mathrm{V}_{2}$ max, suggesting that mitochondrial oxygen uptake is not a factor limiting organismal $\mathrm{VO}_{2} \max$. The $\mathrm{Q}_{10}$ for mitochondrial $\mathrm{V}_{2}$ differed significantly between groups, indicating that differences in $\mathrm{VO}_{2}$ max between endotherms and ectotherms cannot be explained solely on the basis of temperature. The activation energy ( $\left.E_{a}\right)$ of mitochondrial $\mathrm{VO}_{2}$ was significantly higher in endotherms compared to ectotherms. Mitochondrial enzyme activities did not show the same $Q_{10}$ and $E_{a}$ differences as the intact mitochondria. Since enzyme activities were measured on mitochondria disrupted with either detergent or sonication, physical properties of the mitochondrial inner membrane are suggested as being responsible for these differences. 


\title{
THE PHYSIOLOGY AND BIOCHEMISTRY OF ISOLATED SKELETAL MUSCLE MITOCHONDRIA: \\ A COMPARATIVE STUDY
}

\author{
by \\ MARK LOWEL WAGNER
}

A thesis submitted in partial fulfillment of the requirements for the degree of

MASTER OF SCIENCE in BIOLOGY

Portland State University

1989 
TO THE OFFICE OF GRADUATE STUDIES:

The members of the Committee approve the thesis of Mark Lowell Wagner presented March 27, 1989.
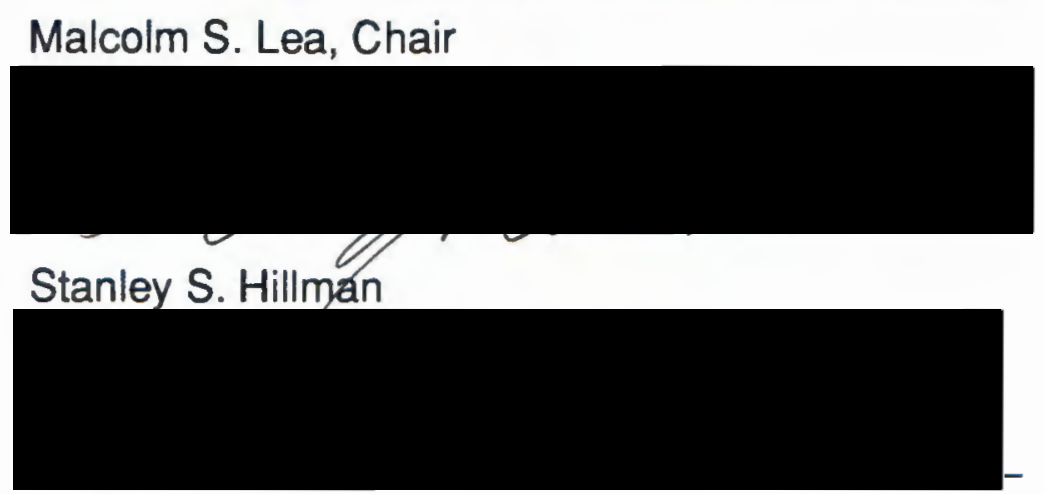

Richard B. Forbes

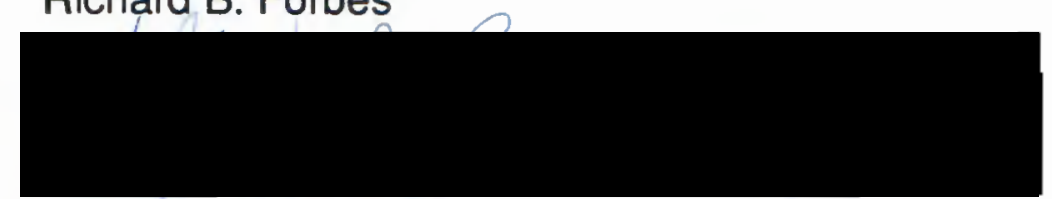

Alfred S. Levinson

APPROVED:

W. Herman Taylor, Chair, Department of Biology

Bernard Ross, Vice Provost for Graduate Studies 


\section{ACKNOWLEDGEMENTS}

I wish to thank the Department of Biology at Portland State University and the Pediatric Metabolic Laboratory at Oregon Health Sciences University for use of space and equipment essential to my research.

I thank the members of my graduate committee; Drs. M.S. Lea, S.S. Hillman, R.B. Forbes and A.S. Levinson, for their patience in reviewing this paper and the much appreciated comments.

The following people contributed significantly to my Masters education and I wish to thank them: Malcolm Lea, Stan Hillman, Larry Crawshaw, Phil Withers, Dick Forbes, Liba Stankova, Leena Mela-Riker, Nancy Kennaway, Lester Newman, Pat O'Neill, Debbie Duffield, Ed Lippert, Peter Chan, Mary Taylor, Neil Buist, Berkley Powell, Jack Feldman, John Reuter, Jon Abramson, Joanne Sanders-Loehr, John Golbeck, Pavel Smejtek, Mark Baustian, Roque Carrero, John Trimm, Wayne Palioca, Mike Hedrick, Rob Drager, Andy Zigmunt, Pete Kimmel, Vijay Balan, Terry Burlingame.

Carole Hallett bore the brunt of my frustration and still loves me. For this I am very, very thankful.

I thank Drs. Hank Harlow and Harold Bergman at the University of Wyoming for their critical remarks on my writing style and 
content and Dr. Jim Collins for help with setting up the statistics.

Lastly, I wish to thank my parents. They have always given great support to my educational endeavors and ambitions. I would be nowhere without their love and encouragement.

This paper is dedicated to the memory of Charlie, Arrow, Junior, Ned and No Foot. 


\section{TABLE OF CONTENTS}

PAGE

ACKNOWLEDGEMENTS

iii

LIST OF TABLES $\ldots \ldots \ldots \ldots \ldots \ldots \ldots \ldots \ldots \ldots \ldots$ vi

LIST OF FIGURES $\ldots \ldots \ldots \ldots \ldots \ldots \ldots \ldots \ldots \ldots \ldots \ldots$ vii

CHAPTER

I INTRODUCTION ..................... 1

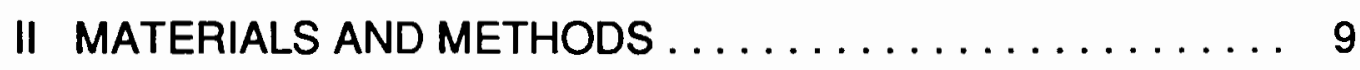

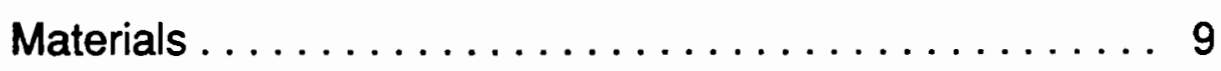

Methods $\ldots \ldots \ldots \ldots \ldots \ldots \ldots \ldots \ldots . \ldots$

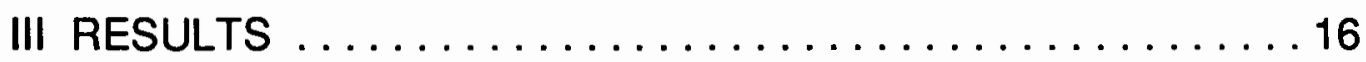

IV DISCUSSION $\ldots \ldots \ldots \ldots \ldots \ldots \ldots \ldots \ldots \ldots \ldots$

$\checkmark$ CONCLUSIONS ..................... 54

VI LITERATURE CITED ................. 56

VII APPENDIX ...................... 64 


\section{LIST OF TABLES}

TABLE

PAGE

I Summary of Mitochondrial $\mathrm{VO}_{2}$

Ila Summary of Mitochondrial Enzyme Activities

per Gram Wet Weight Muscle

Ilb Summary of Mitochondrial Enzyme Activities per nmol Cytochrome $c+c_{1}$

III Activation Energies of Mitochondrial Enzymes

39

IV Mitochondrial Enzyme and $\mathrm{VO}_{2}$ Activity Ratios 


\section{LIST OF FIGURES}

FGURE

PAGE

1a. Mitochondrial $\mathrm{VO}_{2}$ per gram wet weight muscle

1b. Mitochondrial $\mathrm{VO}_{2}$ per nmol cytochrome $\mathrm{c}+\mathrm{c}_{1}$

2. $\mathrm{Log} / \log$ plot of mitochondrial $\mathrm{VO}_{2}$ vs. temperature

3. Arrhenius plot of mitochondrial $\mathrm{VO}_{2}$

4. Cytochrome $\mathrm{c}$ oxidase activity per gram wet weight muscle

5. Succinate cytochrome $c$ reductase activity per gram wet weight muscle

6. Succinate dehydrogenase activity per gram wet weight muscle

7. NADH oxidase activity per gram wet weight muscle

8. Citrate synthase activity per gram wet weight muscle

9. Cytochrome $c$ oxidase activity per nmol cytochrome $c+c_{1}$

32

10. Succinate cytochrome $\mathrm{c}$ reductase activity per $\mathrm{nmol}$

cytochrome $c+c_{1}$

11. Succinate dehydrogenase activity per $\mathrm{nmol}$ cytochrome $c+c_{1}$ 
12. NADH oxidase activity per nmol cytochrome $c+c_{1}$

13. Citrate synthase activity per nmol cytochrome $c+c_{1}$

14. Mitochondrial $\mathrm{VO}_{2}$ vs COX activity

15. Mitochondrial $\mathrm{VO}_{2}$ vs SCc activity

16. Mitochondrial $\mathrm{VO}_{2}$ vs SDH activity

17. Mitochondrial $\mathrm{VO}_{2}$ vs NADHOX activity

18. Mitochondrial ${\nabla \mathrm{O}_{2}}_{2}$ vs CS activity 


\section{INTRODUCTION}

Most of the adenosine triphosphate (ATP) required by vertebrates for locomotion is generated by skeletal muscle mitochondria. Mitochondria require oxygen to generate and maintain the chemiosmotic gradient that drives ATP synthesis. During maximal aerobic activity skeletal muscle mitochondria utilize more than $90 \%$ of the oxygen consumed by an organism (Weibel, 1979). An organism's maximum aerobic capacity ( $(\mathrm{O} 2 \mathrm{max}$ ) can be measured accurately by determining the amount of oxygen consumed during activity. Maximum aerobic capacity can be estimated by measuring the $\mathrm{VO}_{2}$ of muscle homogenates or mitochondria isolated from skeletal muscle, or it can be extrapolated from Vmax of mitochondrial enzymes.

The physiological limit to $\mathrm{VO}_{2}$ max is highly controversial. Saltin (1985) has summarized three distinct views on the limit to maximal aerobic capacity: 1) the limit is a function of cardiovascular ability to deliver oxygen to muscle cells (Hillman 1976, 1980,1982; Hillman, et. al., 1985; Saltin, 1985; Walsberg, et. al., 1986; Schultz, 1988); 2) the limit is within the cells; i.e., the ability of the mitochondria to utilize available oxygen (Holloszy and Booth, 1976; Hoppeler, et.al. 1981a,b; Mathieu, et. al., 1981; 
Hoppeler and Lindstedt 1985; Hoppeler, et. al., 1987) and 3) the limit to $\mathrm{VO}_{2}$ max cannot be attributed to any one single factor because the components of the system are so closely interconnected or the means of measurement are too imprecise to produce a clear answer (Weibel, et. al., 1981; Di Prampero, 1985; Taylor, et. al., 1987a,b ).

Saltin (1985) measured $\mathrm{VO}_{2}$ max in isolated quadriceps muscle of humans. He concluded, on the basis of tissue blood flow at maximal activity, that to perfuse equally the entire muscular system would require a cardiac output of 50 to 60 liters per minute. This is approximately twice the average maximal cardiac output of the human heart (Blomqvist and Saltin,1983). Walsberg, et. al. (1986) measured $\mathrm{VO}_{2}$ max in wild bullfrogs (Rana catesbeiana) and found a two-fold variation closely correlated to ventricular mass and hemoglobin concentration. This variation did not correlate with citrate synthase activity, a proposed indicator of aerobic capacity (Holloszy and Booth, 1976; Putnam and Bennett, 1983), suggesting that cardiovascular oxygen delivery is the limit to $\mathrm{VO}_{2}$ max in anuran amphibians. This finding supports the work of Hillman (1976, 1980, 1982; Hillman, et al, 1985), who experimentally varied cardiac output and hemoglobin concentration in several species of anurans and found them closely correlated with changes in $\mathrm{VO}_{2}$ max. Hillman's work has been criticized as not accurately measuring 
$\mathrm{VO}_{2}$ max because of limitations of his experimental method for eliciting maximal aerobic activity (Marsh and Taigen, 1987). Data extrapolated from calling activity in male gray tree frogs (Hyla versicolor) indicate that $\mathrm{VO}_{2}$ max during calling is higher than during forced activity ( Marsh and Taigen, 1987). Marsh and Taigen (1987) may have measured a species-specific effect, however, since Hillman, et. al. (1985) found $\mathrm{VO}_{2}$ max to be proportional to oxygen transport capacity independent of sex in the toad, Bufo marinus.

It has been shown in mammals of very different body mass that the estimated total number of mitochondria in an organism can be used as a predictor of $\mathrm{V}_{2} \max$ (Hoppeler, et. al., 1981a,b; Mathieu, et. al.,1981; Hoppeler and Lindstedt, 1985; Hoppeler, et. al.,1987; Hudlicka, et. al., 1988). Taylor, et. al. (1981) reported that for several African mammals ranging in mass from 0.5 to 250

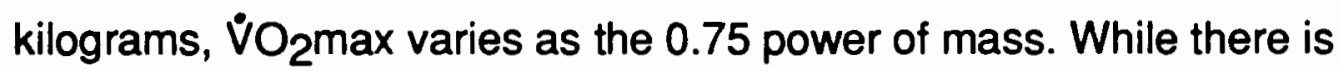
great diversity in the distribution of mitochondria per muscle and per species, the total mitochondrial number correlates with mass-specific $\mathrm{VO}_{2} \max$ ( Mathieu, et. al., 1981). Based on data from several mammalian species, including humans and one bird, Hoppeler and Lindstedt (1985) calculated the mitochondrial $\mathrm{VO}_{2} \max$ to be $3-5 \mathrm{ml} \mathrm{O} / \mathrm{min} \cdot \mathrm{ml}$ mitochondria. They state that organismal $\mathrm{VO}_{2} \mathrm{max}$ can be estimated from the total number of mitochondria in a muscle 
sample extrapolated to total muscle mass and mitochondrial volume.

This finding implies that mitochondria respire at the same rate regardless of body mass or species, at least for those species examined by Hoppeler and Lindstedt (1985). In contrast, recent data suggest that while mitochondrial volume density (mitochondrial volume per muscle fiber volume) and capillary length density (capillary length per muscle fiber volume) are linearly related, they may not be the only factors responsible for differences in $\mathrm{VO}_{2}$ max. For a 2.5 -fold difference in aerobic capacity between aerobic ponies and dogs, and less aerobic calves and goats, only 1.7 times more capillarity was found; the balance of the difference was a 1.5 times higher hematocrit in the aerobic mammals (Hoppeler and Kayar, 1988).

Di Prampero (1985) and Weibel, et. al., (1981) contend that the respiratory system in mammals is so tightly integrated that to isolate one particular component as the definitive limiting factor for ${ }^{\circ} \mathrm{O}_{2}$ max is very difficult. Considerable plasticity is inherent in the respiratory system. The individual components respond differently, but in a coordinated manner - a phenomenon termed symmorphosis- to meet the aerobic demands of the organism (Taylor and Weibel, 1981; Taylor, et. al., 1987a,b). Di Prampero's (1985) conclusion is that the limit to whole body $\mathrm{VO}_{2}$ max depends 
upon cardiac output, however, the way maximal activity is measured may influence the apparent cardiovascular involvement. During one-legged exercise training in man, where relatively few muscle groups are involved, changes in $\mathrm{VO}_{2}$ max were dependent in approximately equal parts on changes in cardiac output and perfusion of the muscle by the peripheral circulation. Changes in mitochondrial oxidative capacity, measured on the basis of succinate dehydrogenase activity, were in excess of the overall change in $\dot{\mathrm{V}}_{2} \max$. Changes in whole body $\mathrm{VO}_{2} \max$, he concludes, were limited mostly by cardiac output ( about $80 \%$ ), while tissue perfusion and mitochondrial oxidative capacity had only a minor involvement in the overall limit to $\mathrm{VO}_{2}$ max.

One weakness in the arguments presented above is that the bulk of the evidence supporting the cellular limit and symmorphosis theories is based on data from experiments on mammals, the evidence for a cardiovascular limit to aerobic capacity is derived mainly from experiments on amphibians. Considering the physiological differences between these groups, a simple model may not suffice to describe limits to aerobic capacity in all animals. This study compares the physiological and biochemical properties of skeletal muscle mitochondria from endotherms and ectotherms. Such information is essential to any comparative study of aerobic 
physiology and may shed light on the limiting factor in aerobic capacity.

Previous studies have shown that the temperature-dependent responses of mitochondrial oxidation from vertebrates of different classes vary as a function of acclimation temperature and class (Lyons and Raison, 1970; Raison, et. al., 1971a,b; Hazel 1972a,b; Roberts et. al., 1972; Pye, 1973; Smith, 1973a,b,c; Pye, et. al., 1976; McMurchie and Raison, 1979; Ohira and Ohira, 1988; Raison, et. al., 1988; Wodtke, 1973, 1974a,b, 1976, 1981). A wide variety of vertebrate mitochondria from liver, heart and skeletal muscle show a discontinuous Arrhenius plot of enzyme activation energy. This discontinuity has been attributed to a temperature induced phase transition in the phospholipid portion of the mitochondrial inner membrane. Roberts, et. al., (1972) found a higher ADP/O ratio and lower $Q_{10}$ in mitochondria from hibernating mammals compared with non-hibernating mammals, suggesting an adaptation for maintaining metabolic function during hibernation and rewarming. Raison, et.al. (1988) found seasonal changes in the transition temperature $\left(T^{*}\right)$ of membrane phospholipids in liver mitochondria from the golden-mantled ground squirrel (Spermophilus lateralis). In contrast, cardiac muscle mitochondria from the same animal did not show this seasonal change: $T^{*}$ was maintained at a temperature well 
below the minimum body temperature of the hibernating animal $\left(<4^{\circ} \mathrm{C}\right.$ ). They (Raison, et.al., 1988) propose that heterothermic endotherms have adaptations which are tissue-specific. Wodtke (1974a,b, 1976, 1981) found species- and tissue-specific differences in succinate, $\beta$-hydroxy butyrate, and glutamate oxidation in fish. Cold acclimation decreased $\mathrm{VO}_{2}$ max in liver mitochondria but increased $\mathrm{V}_{2}$ max in skeletal muscle mitochondria.

Pye, et. al. (1976) reported that cold acclimation in a fish (Tench, Tinca tinca) leads to a shift in in vitro substrate utilization dependent upon the tissue studied. For example, liver mitochondria respire maximally in the presence of succinate, while skeletal muscle mitochondria maintain a maximum rate of respiration using $\alpha$-ketoglutarate as substrate. Ohira and Ohira (1988) found increased mitochondrial enzyme activities and decreased ATP concentrations, but no effect on the rate of glycolysis in $4^{\circ} \mathrm{C}$ acclimated frogs. The data suggest substantial differences in the temperature-dependent properties of mitochondria from various vertebrate classes and between species within the same class. These findings indicate that great care must be taken when interpreting $\dot{\mathrm{V}}_{2}$ max in different classes of vertebrates.

While there has been an abundance of work comparing the aerobic capacity of vertebrates within a particular class, very little 
work has involved comparisons between classes of vertebrates or between ectotherms and endotherms in general ( Alp, et. al., 1976;

Driedzic, et.al.,1987). It is essential to any comparative statement on aerobic metabolism that the criteria used to judge variability, limitations and capacity be based on indices which represent $\grave{V}_{2}$ max independent of class. Since mitochondria are the terminal oxygen acceptors, they can be used to estimate the aerobic potential of the tissue from which they were isolated. Therefore, the objectives of this study are:

1) to describe the physiological and biochemical responses of skeletal muscle mitochondria from four vertebrate classes to temperature change,

2) to present an enzyme activity profile of the muscle mitochondria and

3) propose an enzyme assay that best represents the physiological $\mathrm{VO}_{2}$ max of the muscle mitochondrion independent of class. 


\title{
MATERIALS AND METHODS
}

\section{MATERIALS}

\begin{abstract}
All inorganic salts and acids used were of reagent grade and obtained from various sources. Organic compounds were of the highest available purity and obtained from Sigma Chemical Company.
\end{abstract} Animals were obtained from either local sources ( rats, Rattus norvegicus and rock doves, Columba livia); provided by Dr. S. S. Hillman ( giant toads, Bufo marinus ), or caught at a local trout farm ( rainbow trout, Salmo gairdnieri) All animals were adults.

\section{METHODS}

Mitochondrial isolation:

Mitochondria were prepared from skeletal muscle involved in locomotion (thigh muscles from rats and toads, breast muscle from the birds, epaxial muscle from the trout). To ensure adequate mitochondria for study, muscle from toads and fish was pooled from two individuals for each mitochondrial preparation. All animals were killed either by decapitation after mild $\mathrm{CO}_{2}$ anesthesia (rats and birds) or by pithing (toads and fish). Skeletal muscle was quickly removed, placed in a preweighed beaker of ice cold sucrose wash 
medium (SET medium: 250mM Sucrose, 10mM Tris-HCl , 2mM EDTA:

$\mathrm{pH} 7.4)$ and the wet weight determined. The tissue was coarsely chopped with scissors and the medium poured off. The tissue was rinsed once with SET medium, resuspended in one volume $(1 \mathrm{ml}$ per gram wet weight tissue) SETH medium ( SET with $501 \mathrm{U} / \mathrm{ml}$ sodium heparin) and chopped finely with scissors. The volume was doubled with SETH, then trypsin ( Sigma type: III, $0.5 \mathrm{mg} / \mathrm{gram}$ wet tissue weight) was added and the suspension stirred gently in an ice-water bath for 30 minutes, after which Soybean Trypsin Inhibitor (Sigma type: I-S, $0.5 \mathrm{mg} / \mathrm{g}$ wet wt.) was added and the suspension diluted to twenty volumes. The tissue digest was then homogenized by 3 bursts of ten seconds each with a mechanical tissue homogenizer (Polytron). Mitochondria were then isolated by the modified Bookleman method described by Fischer, et. al. (1985a). The homogenate was centrifuged at $600 \mathrm{~g}$ for $10 \mathrm{~min}$ and the resultant supernatant centrifuged at $10,000 \mathrm{~g}$ for $10 \mathrm{~min}$ to yield a mitochondrial pellet. This crude mitochondrial pellet was resuspended in $20 \mathrm{ml} \mathrm{SETH}$ and centrifuged for $10 \mathrm{~min}$ at $1000 \mathrm{~g}$. The resultant supernatant was centrifuged $10 \mathrm{~min}$ at $10,000 \mathrm{~g}$. The pellet was resuspended in $10 \mathrm{ml}$ SET and centrifuged again at $10,000 \mathrm{~g}$ for $10 \mathrm{~min}$. The final pellet was diluted with SET $(0.05 \mathrm{ml} / \mathrm{g}$ wet wt tissue) and gently homogenized with a ground glass pestle to disperse the pellet. Aliquots taken for biochemical analysis were 
frozen immediately on dry ice; the remaining sample was placed in an ice bath until used.

\section{Polarography:}

The oxygen uptake medium consisted of $0.15 \mathrm{M} \mathrm{KCl}, 0.01 \mathrm{M}$ Tris- $\mathrm{HCl}$ and $0.03 \mathrm{M} \mathrm{KPi}$ at $\mathrm{pH} 7.4$ as measured at room temperature. Oxygen uptake studies were conducted at 15,25 and $35^{\circ} \mathrm{C}$ in a water-jacketed cell equipped with a Clark-type oxygen electrode and a Yellow Springs oxygen monitor (model 55). A 50 $\mu$ l aliquot of mitochondria was added to $1.3 \mathrm{ml}$ of air-equilibrated oxygen uptake medium and the chamber was sealed. Substrate (glutamate/ malate) and ADP were added through a $1 \mathrm{~mm}$ diam. capillary opening. The final substrate concentrations were $10 \mathrm{mM}$ glutamate and $5 \mathrm{mM}$ malate. The final concentration of ADP was $370 \mu \mathrm{M}$. The concentration of oxygen in solution was determined at $15^{\circ}, 25^{\circ}$ and $35^{\circ} \mathrm{C}$ by NADH oxidation using sonicated beef heart mitochondria resuspended in oxygen uptake medium as described by Chappell (1964).

\section{Enzyme Assays:}

All enzyme assays were conducted in a Beckman DU7 UV/Vis spectrophotometer equipped with a temperature controlled cuvette holder. Unless otherwise specified, assays were conducted at 35,25 and $15^{\circ} \mathrm{C}$ on once-thawed mitochondria diluted to $1 \mathrm{mg} \mathrm{protein} / \mathrm{ml}$ 
with SET containing $0.1 \%$ Tween 80 and kept on ice until used.

Cytochrome c oxidase activity was assayed by a modified version of the the method of Wharton and Tzagoloff (1967) as described by Darley-Usmar, et. al.(1983). Samples were allowed to incubate in the reaction medium (50mM Phosphate buffer with $0.5 \%$ Tween $80, \mathrm{pH} 7.0$ ) for $5 \mathrm{~min}$ at $30^{\circ} \mathrm{C}$ before beginning the reaction by the addition of ferrocytochrome $c$. The initial concentration of ferrocytochrome c was $10 \mu \mathrm{M}$.

Activities of succinate dehydrogenase and succinate: cytochrome $\mathrm{c}$ reductase were estimated as described by Fischer et. al. (1985b). The mitochondria were activated before assay by incubation for $30 \mathrm{~min}$ at $30^{\circ} \mathrm{C}$ in Phosphate/Tween buffer $(50 \mathrm{mM}$ potassium phosphate $/ 0.5 \%$ Tween- $80, \mathrm{pH} 7.4$ ) with $20 \mathrm{mM}$ succinate after which the suspension was stored on ice and aliquots taken for assay as described below. The final concentration of Tween in the assay was $0.01 \%$.

Succinate: cytochrome $\mathrm{c}$ reductase was assayed by following the reduction of ferricytochrome $c$ at $550 \mathrm{~nm}$. A millimolar extinction coefficient of 27.6 was used (Fischer, et. al., 1985b).

Succinate dehydrogenase activity was estimated by following the reduction of 2,6-dichlorophenol indophenol (DCIP) at $600 \mathrm{~nm}$. Phenazine methosulfate $(1 \mathrm{mM})$ was used as the primary electron acceptor. The millimolar extinction coefficient for reduced DCIP is 
19.1 (Fischer, et. al., 1985b).

For NADH oxidase mitochondria were diluted to $1 \mathrm{mg} / \mathrm{ml}$ in SET and the rotenone sensitive (electron transport) activity determined by the reduction of NADH at $340 \mathrm{~nm}$ as described by Fischer, et. al. (1986). The millimolar extinction coefficient for NADH is 6.22 (Fischer, et. al., 1986).

Citrate synthase activity was estimated according to a modified method from Srere (1969) as described by Putnam and Bennett (1983). Mitochondria diluted to $1 \mathrm{mg} / \mathrm{ml}$ with SET with $0.1 \%$ Tween 80 were frozen/thawed 3 times before use. The assay follows the reduction of dithio-bis-nitrobenzoic acid (DTNB) at $412 \mathrm{~nm}$. The millimolar extinction coefficient for reduced DTNB is 13.6 (Srere, 1969).

Cytochrome $c+c_{1}$ concentrations were determined on mitochondria diluted to $1 \mathrm{mg} / \mathrm{ml}$ with Phosphate/Tween buffer (50mM phosphate/ 0.5\% Tween-80, pH 7.0). Difference spectra (oxidized minus reduced) were conducted at $30^{\circ} \mathrm{C}$. Samples were reduced by addition of $10 \mathrm{mM}$ Succinate $(\mathrm{pH} 7.4)$ and a few grains of sodium dithionite. Cytochrome $\mathrm{c}+\mathrm{c}_{1}$ concentrations were calculated as described by Bookelman, et. al. (1978).

Mitochondrial yield was determined by comparing the citrate synthase activity of the muscle homogenate and of the isolated mitochondria at $25^{\circ} \mathrm{C}$ as described above. Muscle homogenate was 
diluted 1:10 with SET/Tween-80 and prepared as described above.

Protein concentrations were determined by the method of Lowry, et. al. (1951) with defatted crystalline BSA used as a standard. The final reaction mixture for protein determination contained $0.8 \%$ sodium dodecyl sulfate (SDS). Protein concentrations were calculated according to the method of Cookley and James as described in Peterson (1977).

The data are expressed in units ( $\mu$ moles $/ \mathrm{min}$ ) per nmole cytochrome $c+c_{1}$ or per gram wet weight muscle as calculated from yield determinations which are based on assays of citrate synthase activity in the muscle homogenate and crude mitochondrial pellet. Yield determinations could not be based on homogenate cytochrome concentration due to interference from non-mitochondrial cytochromes which absorb light at or near the absorbance range of mitochondrial cytochrome $c+c_{1}$. For comparison with published figures for organismal $\mathrm{VO}_{2} \mathrm{max}$, mitochondrial $\mathrm{VO}_{2}$ is also used to calculate $\mathrm{mlO}_{2}$ per hour per gram body weight as described below (see Discussion). A respiratory control ratio (RCR) was determined immediately after mitochondrial isolation by the method of Chance and Williams (1959), except that to ensure maximum oxygen uptake rates for mitochondria from all animals studied, ADP and substrate were added in such excess that State IV (high [substrate], low [ADP], high [ATP]) respiration was not attained; therefore control ratios 
are rates of oxygen uptake of State III (high [substrate], high [ADP]) divided by State II (high [substrate], no ADP) as described by Anderson (1986). Preparations with RCRs below six were discarded.

Activation energies were calculated from Arrhenius plots of mitochondrial $\mathrm{VO}_{2}$ and enzyme activity as described in Lyons, et. al. (1974).

\section{Statistics:}

Data were tested for statistical difference with Student's two-tailed t-test and one- and two-way ANOVA using the StatWorks ${ }^{\text {TM }}$ statistical package on an Apple Macintosh. Differences were considered statistically significant at or above the $95 \%$ confidence interval. 


\section{RESULTS}

Mitochondrial $\mathrm{VO}_{2}$, measured at the three treatment temperatures and expressed as described above, is summarized in Table l. Mitochondrial $\mathrm{VO}_{2}$ per gram muscle (Figure 1a) differs significantly $(p \leq 0.05)$ between the endotherms and ectotherms tested at all treatment temperatures. However, when expressed per nmole cytochrome $c+c_{1}$ (Figure $1 b$ ) there are significantly greater differences $(p \leq 0.05)$ in $\mathrm{VO}_{2}$ between the rock doves and rats, and between the trout and toads, than between endotherms and ectotherms. Mitochondrial $\mathrm{VO}_{2}$ in rock doves was significantly lower $(p \leq 0.001)$ than in all other animals tested.

Double logarithmic plots of $\mathrm{VO}_{2}$ and temperature ( Figure 2) show significantly steeper slopes $(p \leq 0.01)$ for endotherms compared to ectotherms; in addition the trout had a significantly lower slope than the toads $(p \leq 0.05)$.

The endotherms had significantly higher $Q_{10}$ values in each temperature range than ectotherms ( $p \leq 0.01$; Table 1$)$. Over the temperature range studied, Arrhenius plots of mitochondrial $\mathrm{VO}_{2}$ show significantly higher $(p \leq 0.001)$ activation energies $\left(E_{a}\right)$ in endotherms than in ectotherms ( Figure 3, Table I). There are no significant differences in $E_{a}$ or $Q_{10}$ between the species within 
either endothermic or ectothermic groups. 


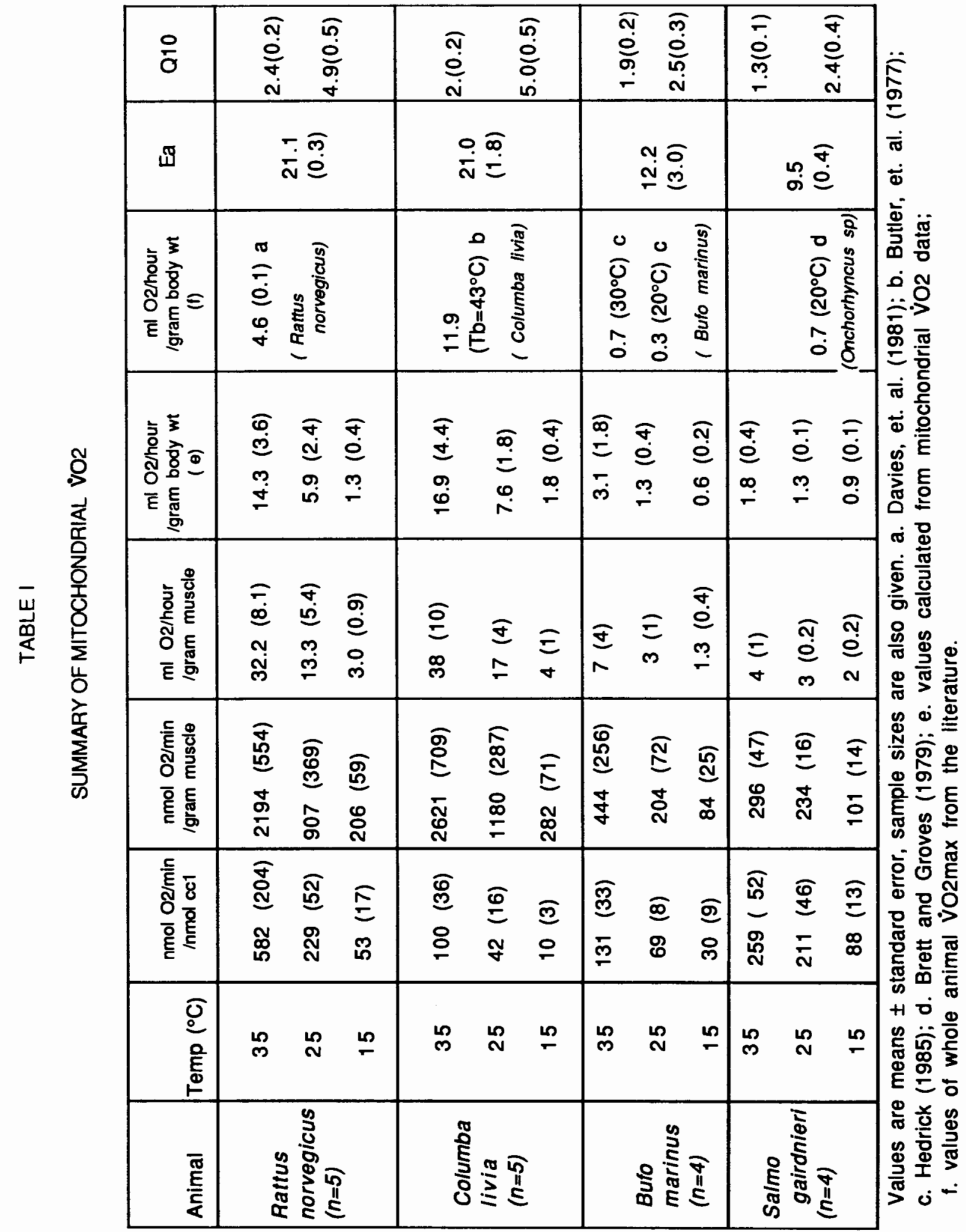




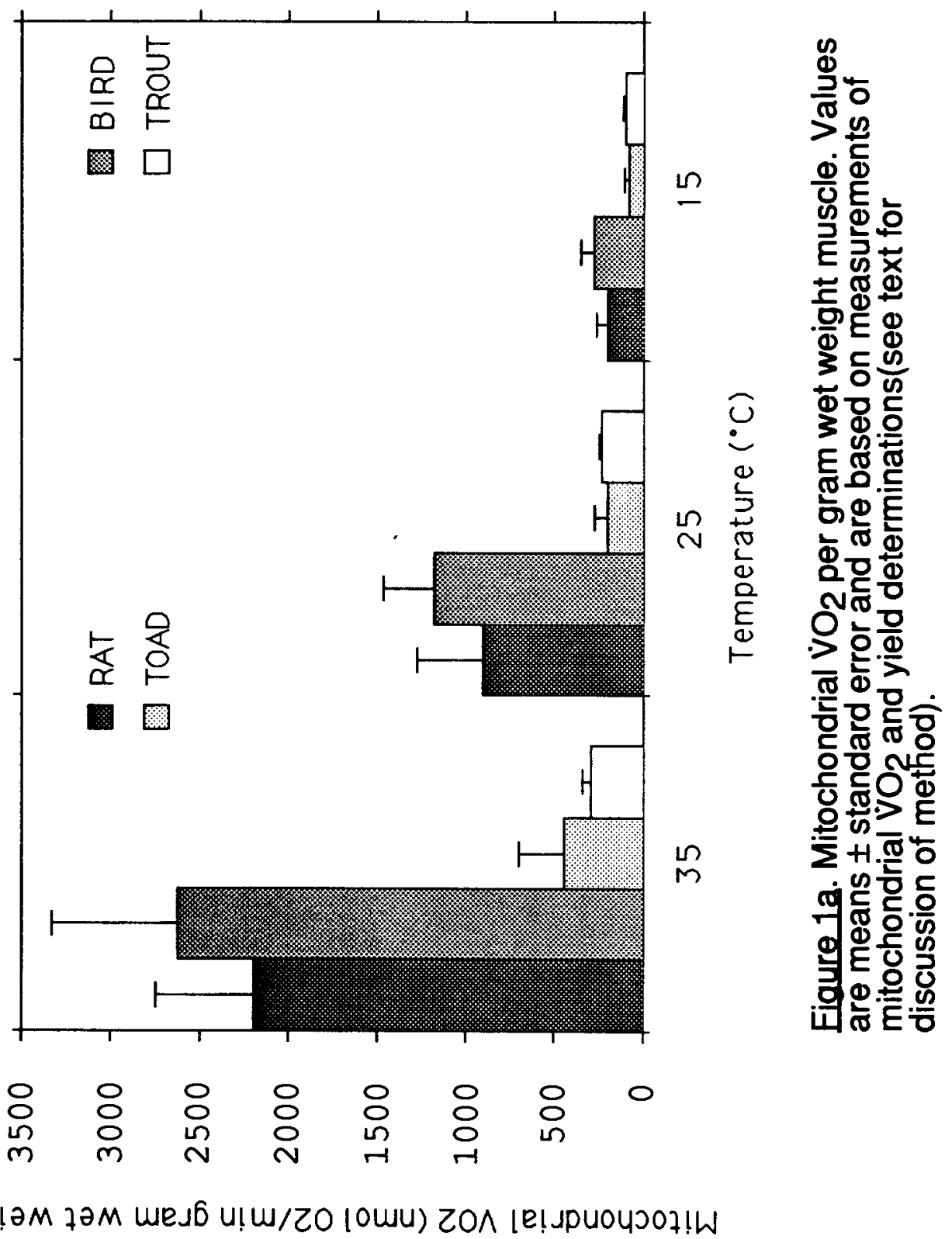




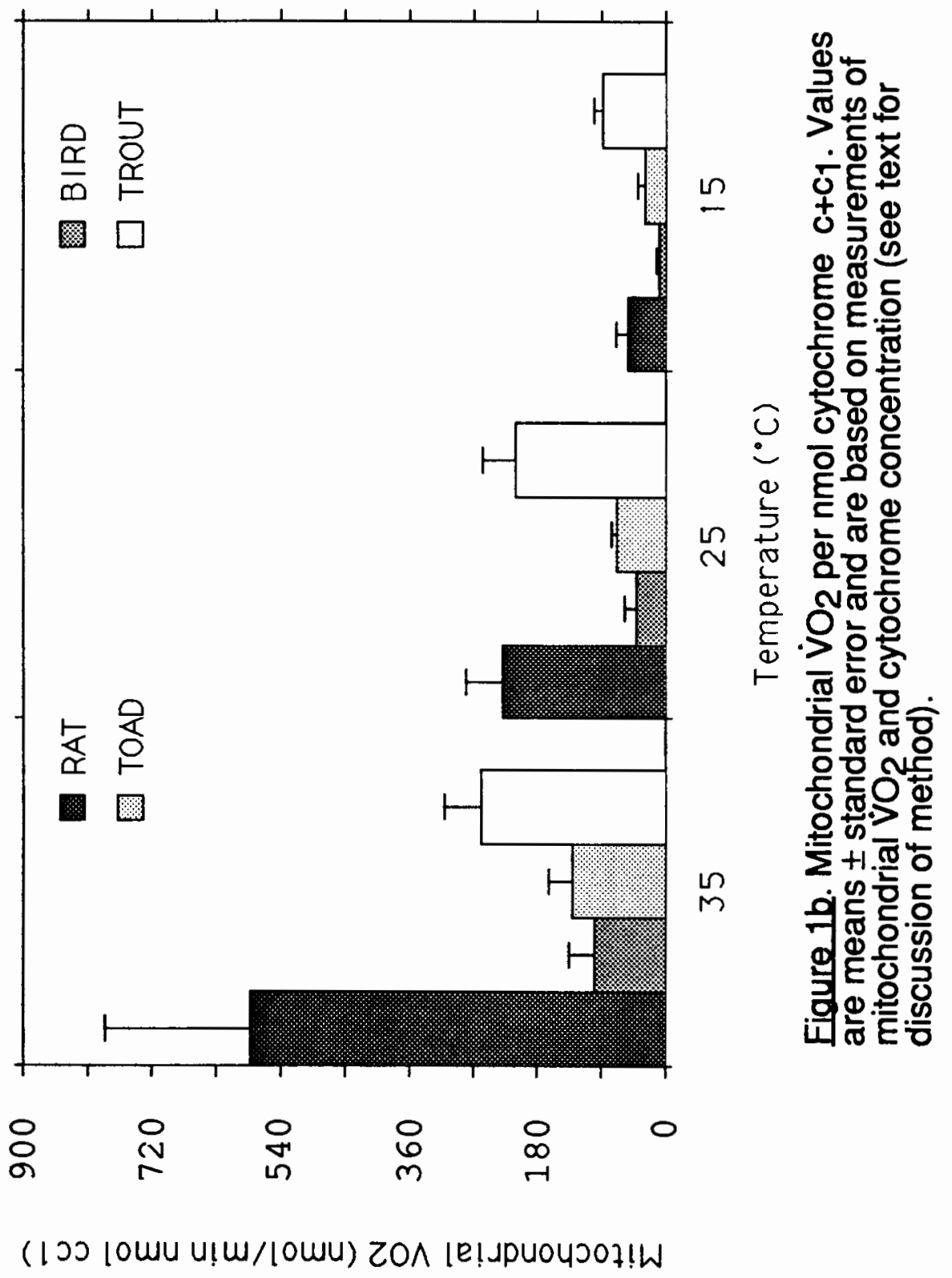




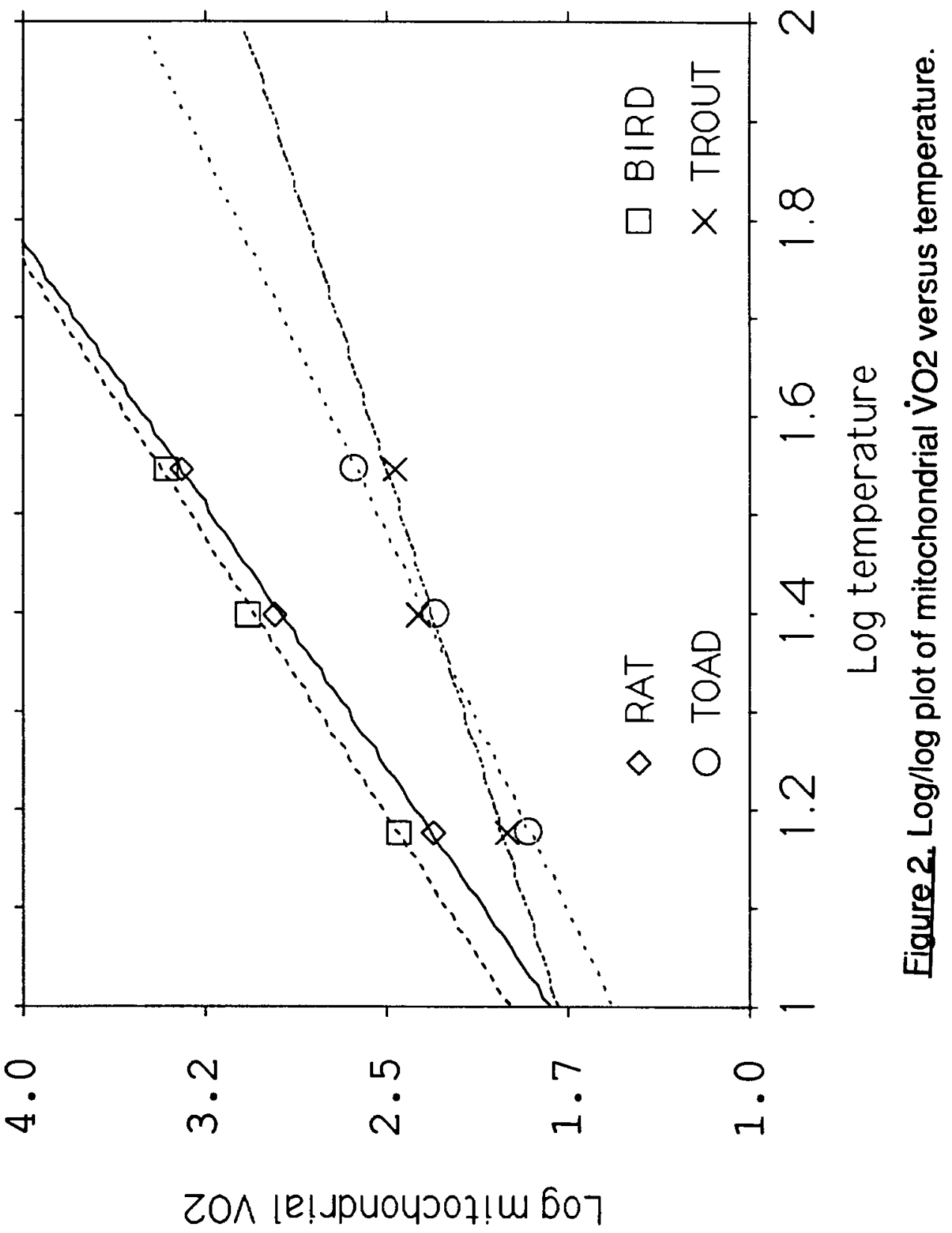




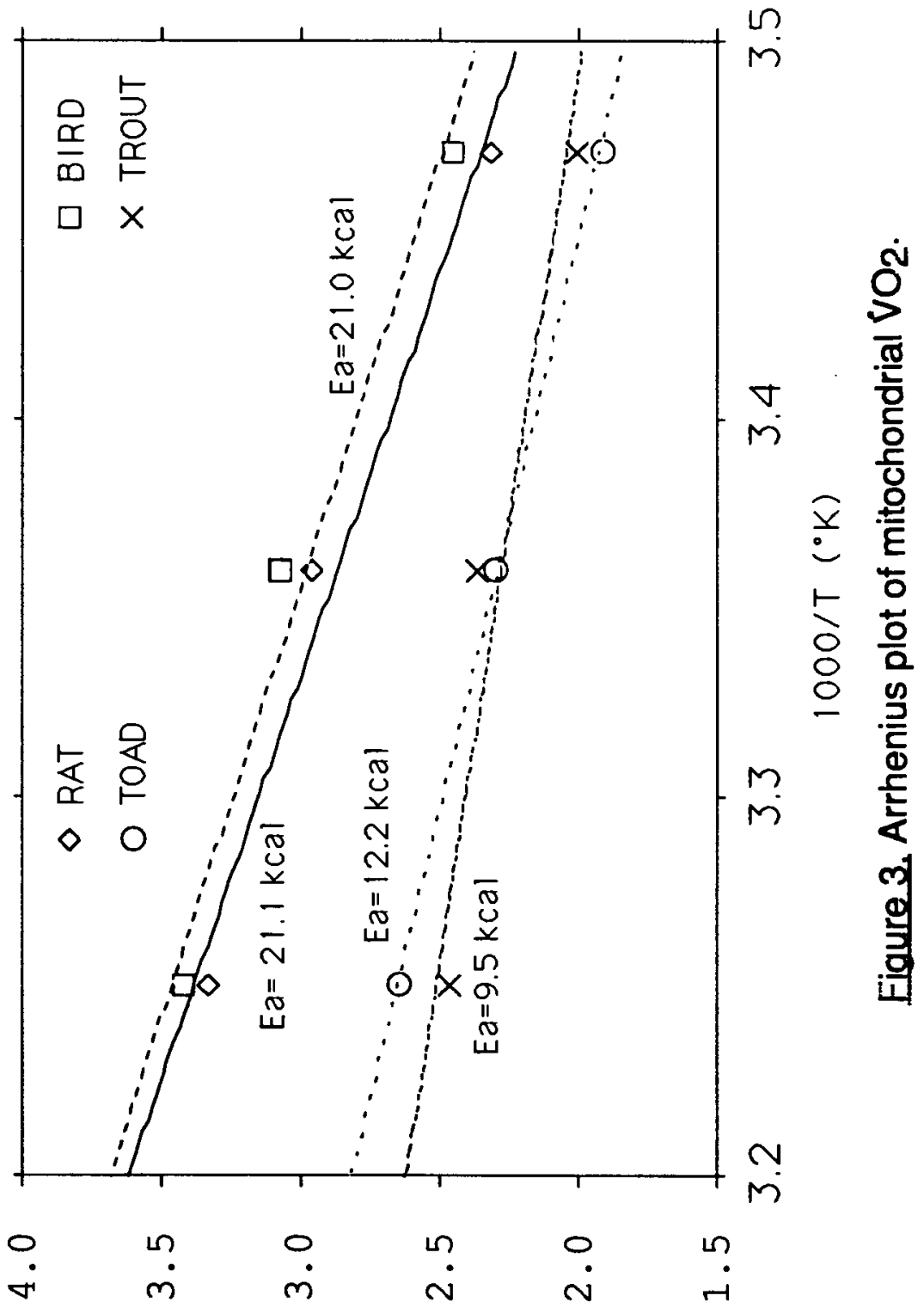

ZO^ [e!.jpuoyวoł!W 607 
Table II summarizes mitochondrial enzyme activities. The enzyme activities represent components of the electron transport system (ETS) and tricarboxylic acid (TCA) cycle. Citrate synthase is an enzyme of the TCA cycle located in the mitochondrial matrix. Cytochrome c oxidase is Complex IV of the ETS, succinate: cytochrome c reductase comprises complexes II and III of the ETS while succinate dehydrogenase consists of two subunits $\left(\mathrm{SD}_{1}\right.$ and $\mathrm{SD}_{2}$ ) of complex II. NADH oxidase measures the activity of complexes I,III and IV of the ETS as a complete system. All ETS enzymes are located in or on the mitochondrial inner membrane. For all enzymes tested and at all temperatures, activities per gram were significantly higher in birds ( $p \leq 0.001)$ than in all other animals ( Table lla and Figures 4-8).

Where possible, enzyme activities were compared to published values. The activities of $\mathrm{CS}, \mathrm{SDH}$ and $\mathrm{COX}$ were comparable to published figures (Alp, et. al., 1979; Davies, et. al., 1981; Putnam and Bennett, 1983). NADHOX activity measured in rat muscle mitochondria was an order of magnitude higher than reported by Davies, et al. (1981). Their activity, however, represents a measurement from intact mitochondria while the activity reported here is determined on a sonicated mitochondrial preparation allowing increased availability of NADH to the oxidase system. Activities expressed per nmole cytochrome $c+c_{1}$ (Table llb) 
showed a more variable pattern. Rainbow trout have significantly

higher cytochrome c oxidase (COX) activity per nmol cytochrome $c+c_{1}$ than all other animals at all temperatures (Figure 9). 


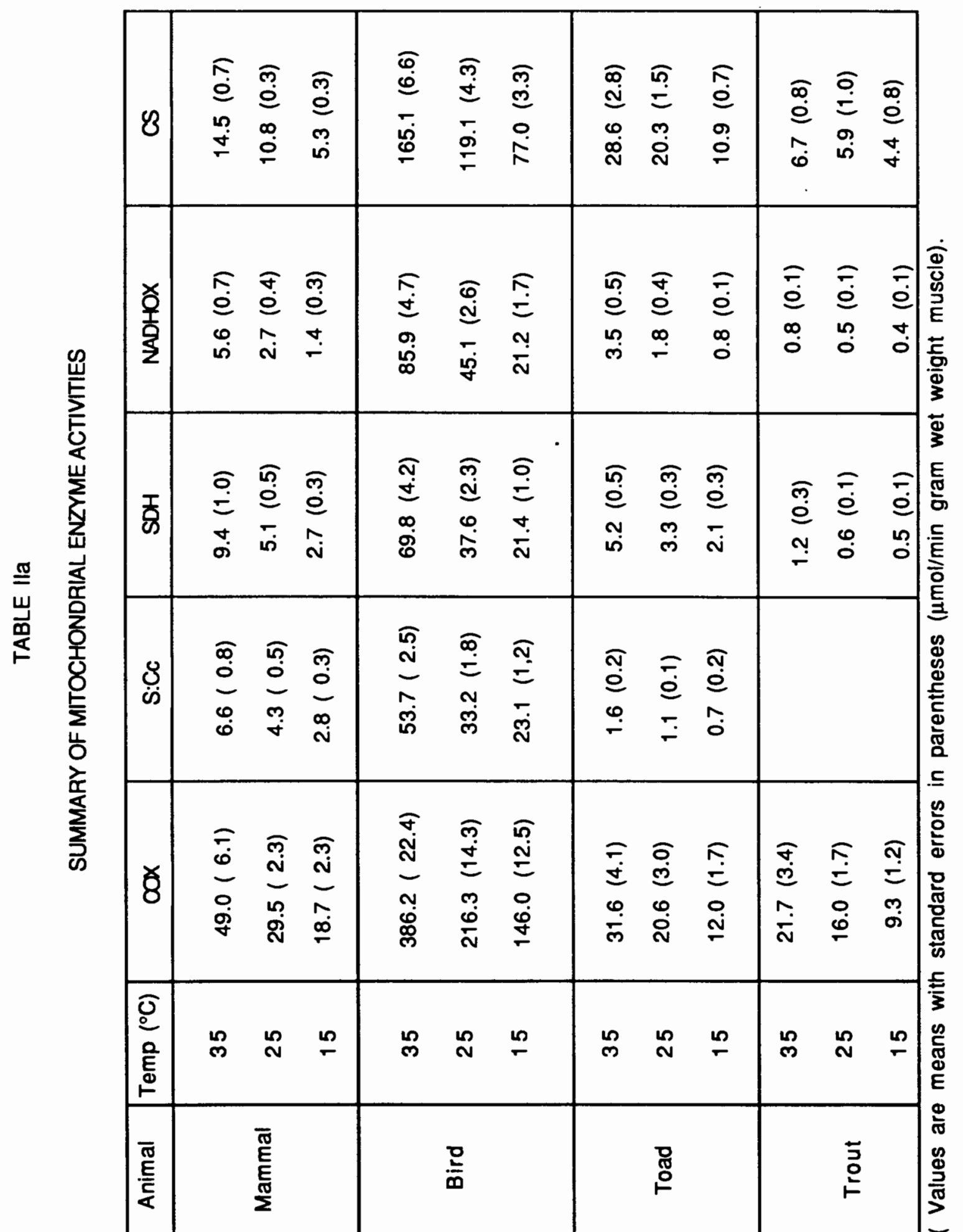




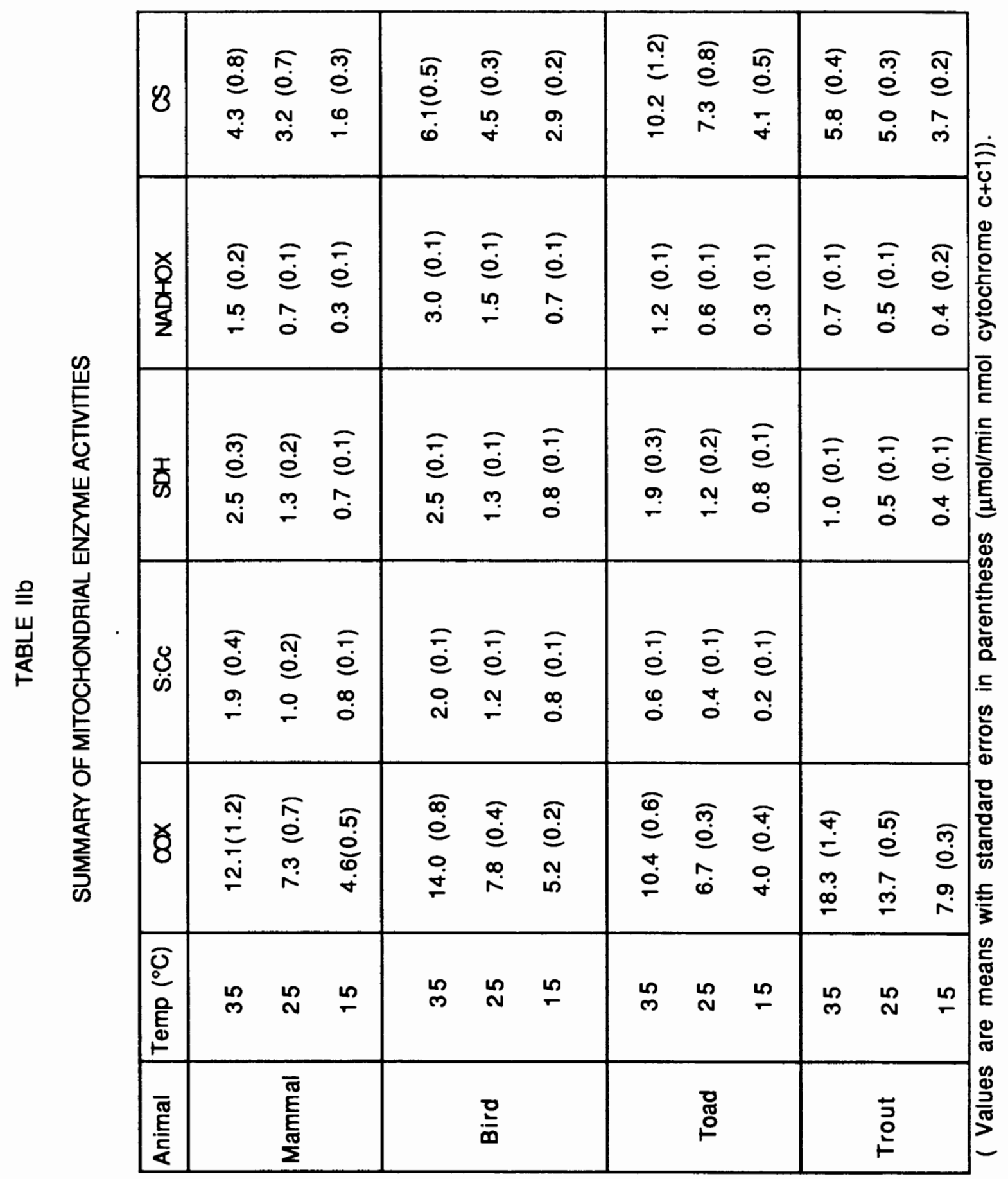




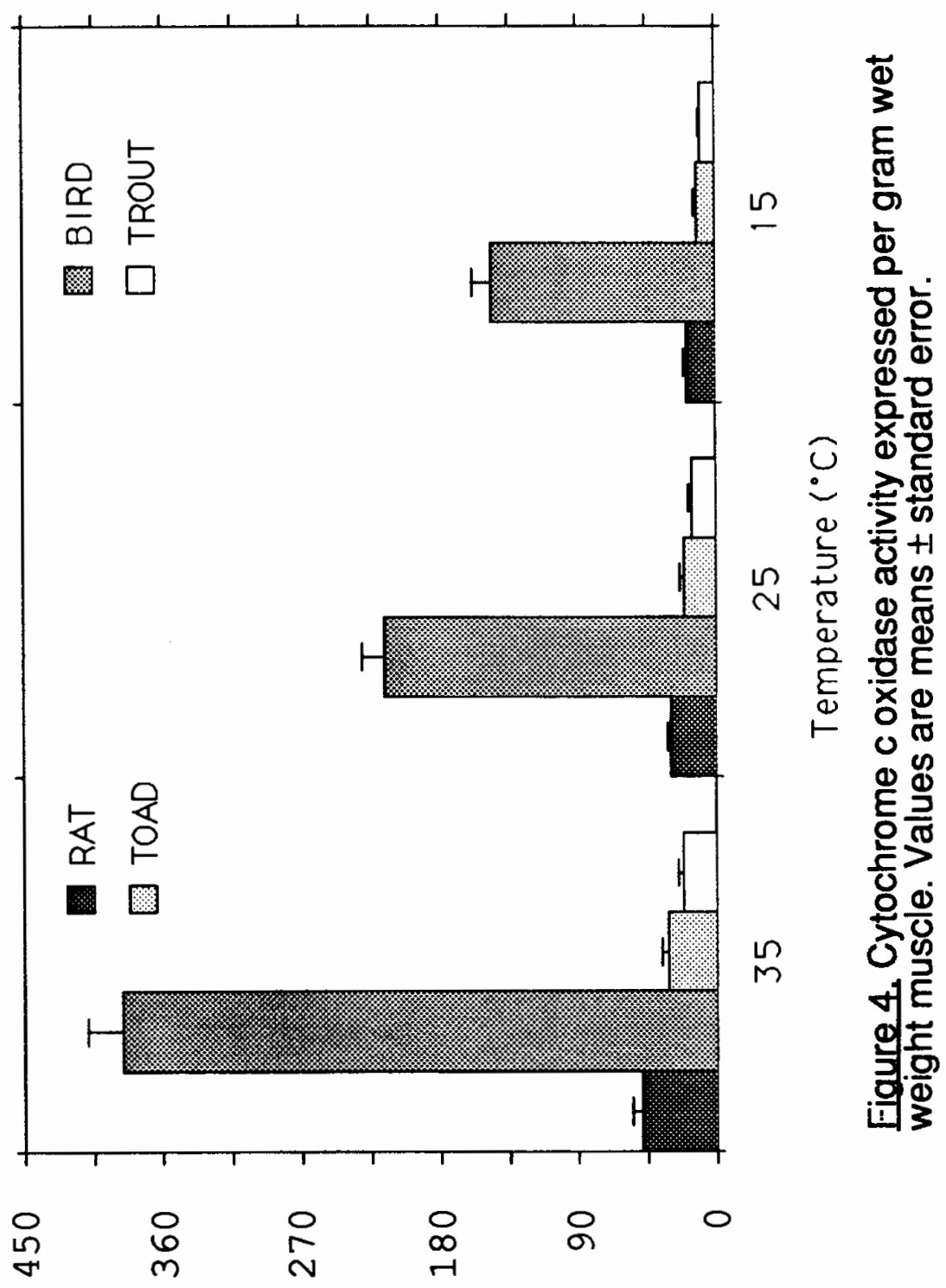

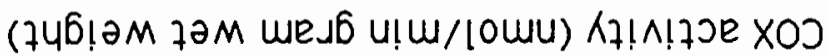




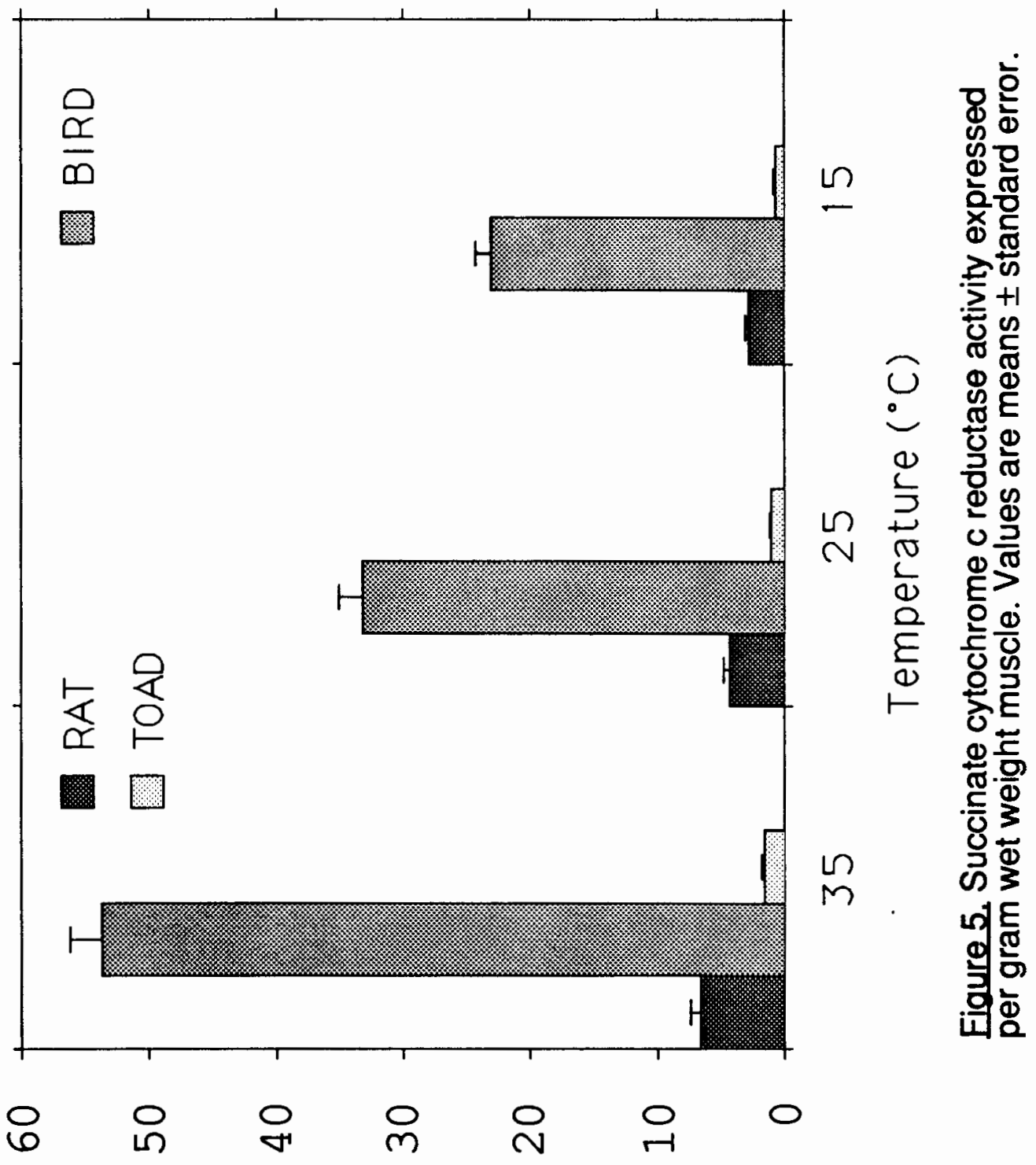

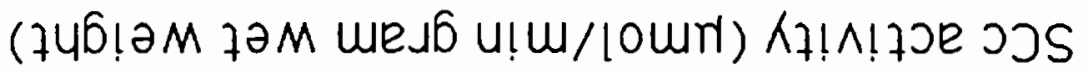




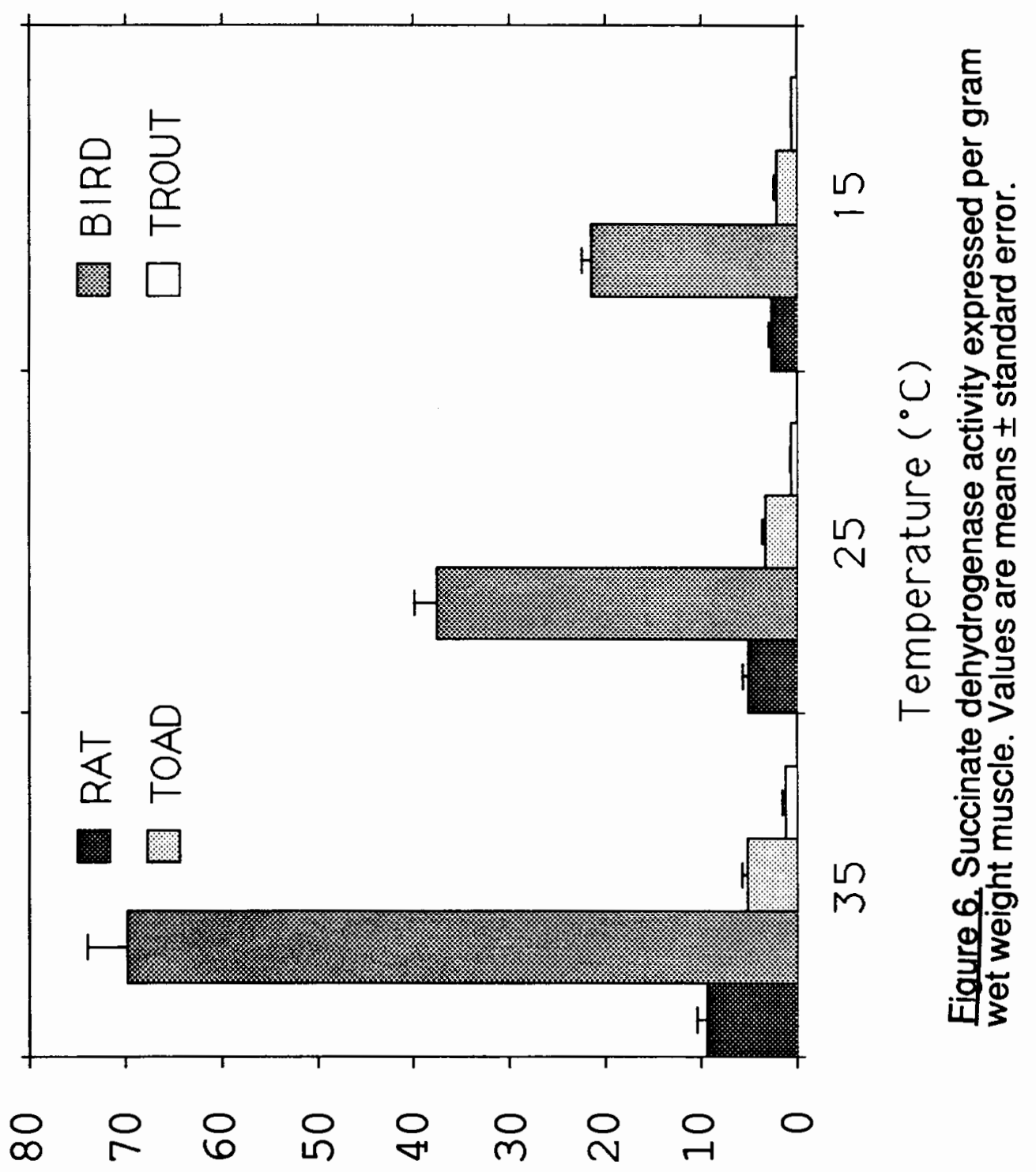

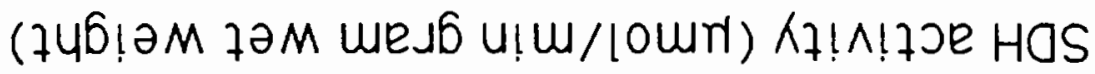




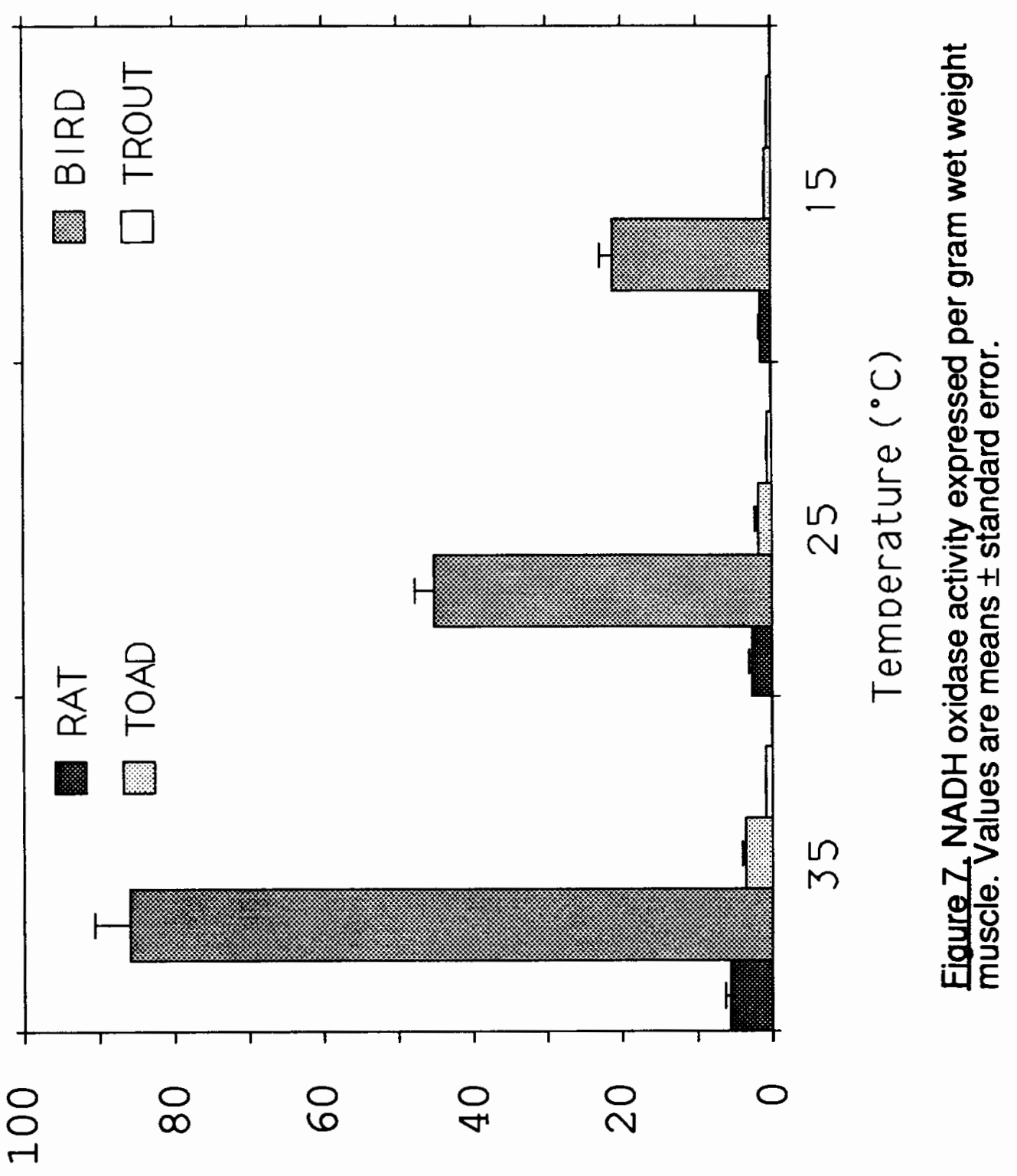

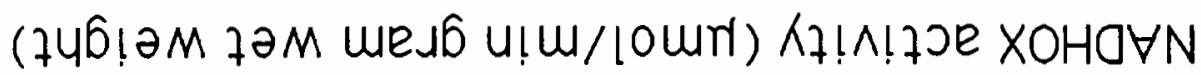




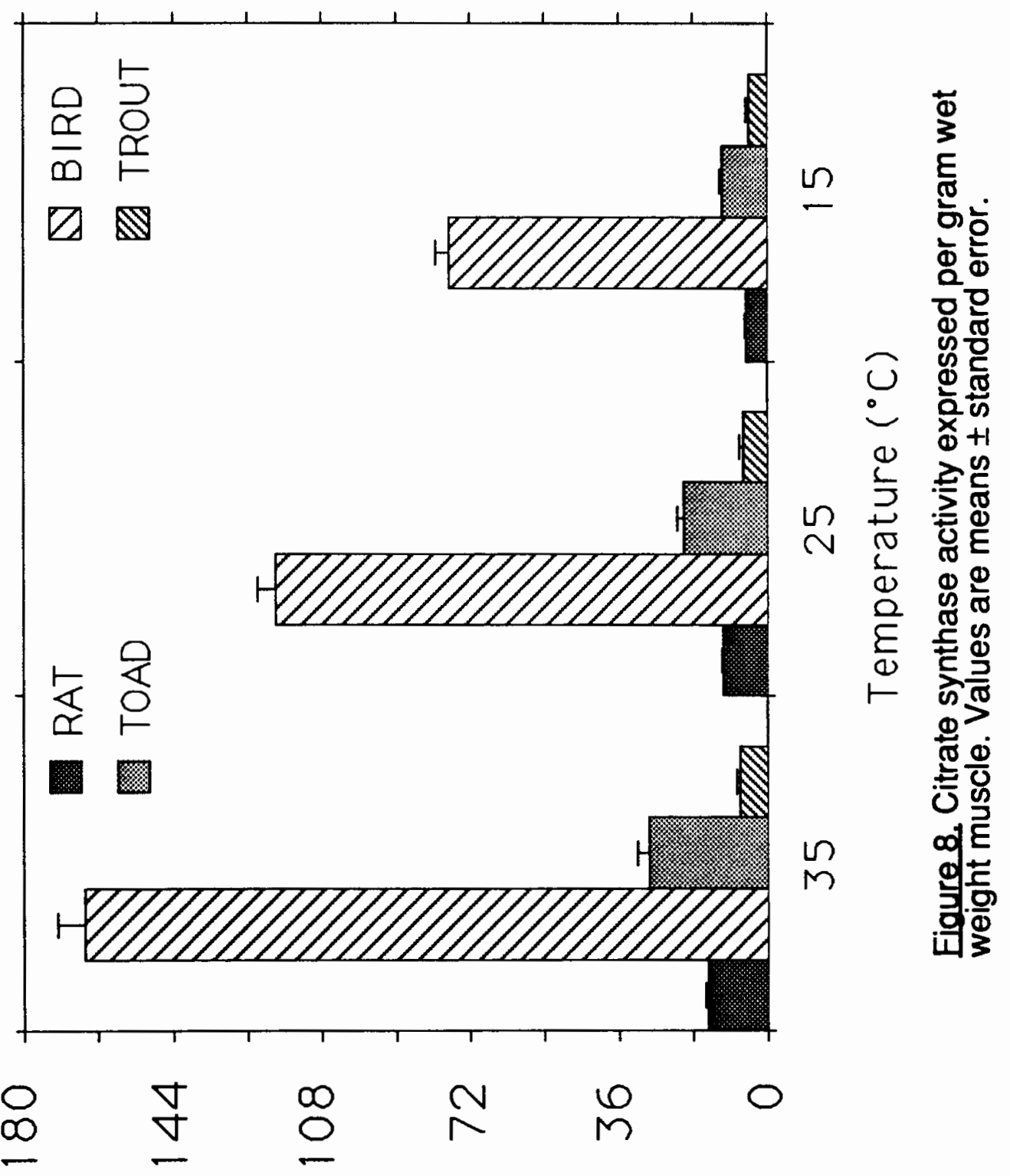

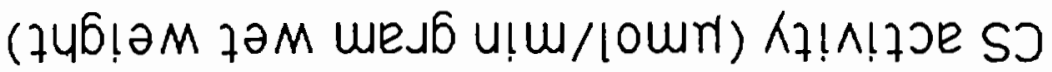




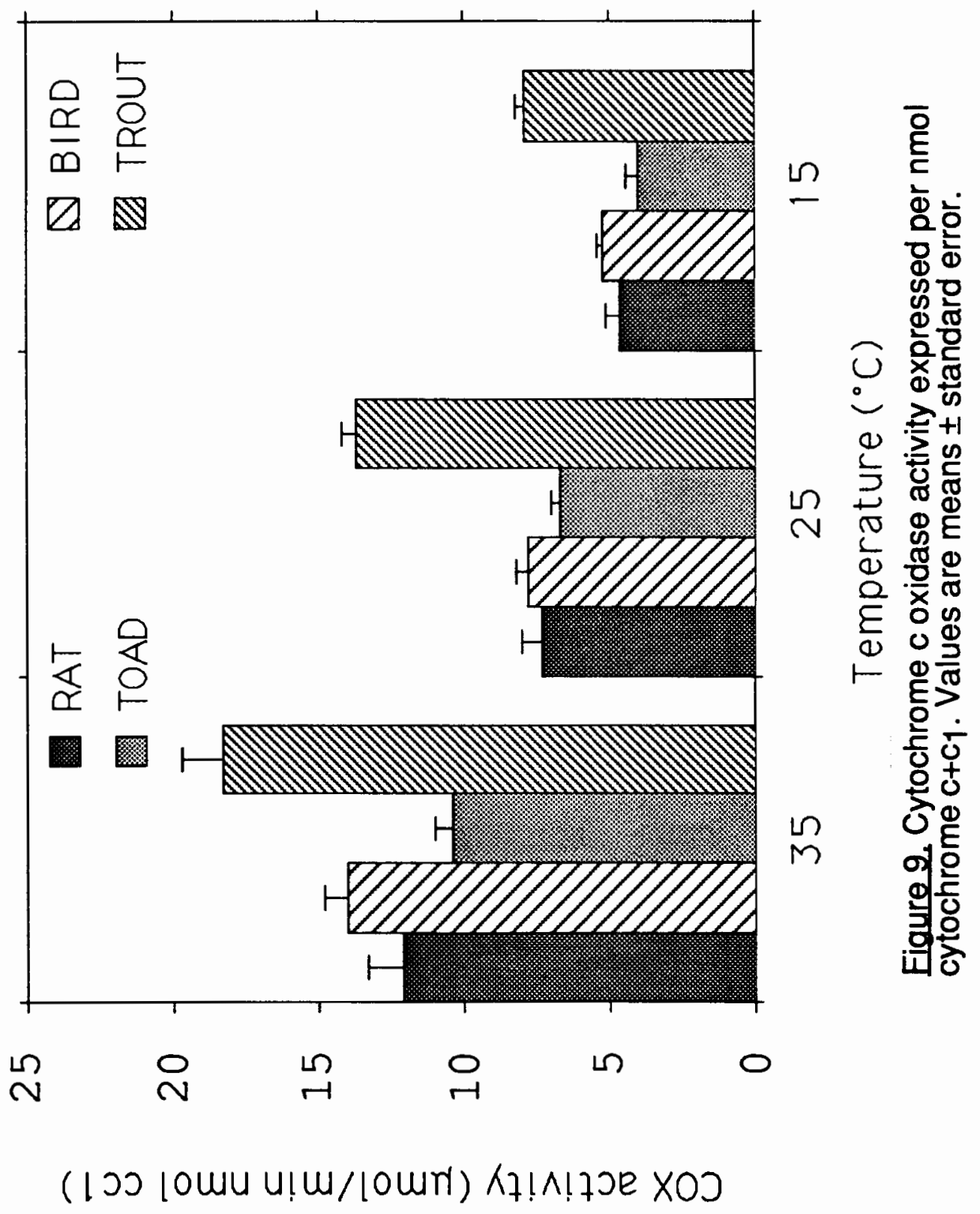


The endotherms have significantly higher succinate: cytochrome $c$ reductase (SCC) activities than do the ectotherms (Figure 10); SCC activity was too low to distinguish from background scattering in trout mitochondria. Succinate dehydrogenase (SDH) activity is significantly lower ( $p \leq 0.001)$ in trout, compared to all other animals tested and lower in the ectotherms than in the endotherms at $35^{\circ} \mathrm{C}$ ( Figure 11). NADH oxidase (NADHOX) activity was highest in the birds at $35^{\circ}$ and $25^{\circ} \mathrm{C}$ (figure 12) and similar in all species tested at $15^{\circ} \mathrm{C}$. Citrate synthase (CS) activity per nmol $\mathrm{C}+\mathrm{C}_{1}$ is significantly higher in toads at $35^{\circ}$ and $25^{\circ} \mathrm{C}$ (Figure 13) and similar in all species tested at $15^{\circ} \mathrm{C}$. Values for $Q_{10}$ were not significantly different among the enzymes studied.

Enzyme activation energies $\left(E_{a}\right)$ for the endotherms and ectotherms were not significantly different for COX, CS or NADHOX (Table III). The $E_{a}$ for SDH was significantly higher $(p \leq 0.001)$ in the endotherms than the ectotherms. The $E_{a}$ for CS was significantly $(p \leq 0.05)$ lower in trout than in toads and lower in rock doves than in rats ( $p \leq 0.05$ ), while rats and toads had similar activation energies. The slopes of double logarithmic plots of enzyme activity versus temperature ( not shown) were not significantly different for COX, SCc and SDH. Trout had significantly lower $(p \leq 0.05)$ slopes for NADHOX and CS when compared to the other animals. Activity ratios were calculated to establish patterns which 
might not be apparent from analysis of comparative data (Table IV). The ratios of NADHOX to CS,SDH to CS, CS to COX and NADHOX to COX were significantly higher in endotherms compared to ectotherms ( $p \leq$ 0.05). While the ratio of SDH activity to COX activity differed significantly in endotherms compared to ectotherms; this difference was due to a significantly lower ratio in the trout when compared to all other animals tested, while the toads were not significantly different from the endotherms. Other ratios differed between species and are summarized in Table IV.

The relationship between enzyme activity and $\mathrm{VO}_{2}$ was examined in order to determine an enzyme assay that best represents mitochondrial $\mathrm{VO}_{2}$, for all animals studied. Least squares regression analyses of $\mathrm{VO}_{2}$ versus enzyme activity for all groups are presented in Figures 14 through 18. For $\mathrm{VO}_{2}$ versus $\mathrm{COX}$ and $\mathrm{CS}$, the mammal differed significantly ( $p \leq 0.05$ ) from all other groups; the trout had significantly higher $(p \leq 0.05)$ slopes with respect to CS activity than the birds or toads. The birds had significantly lower ( $p$ $\leq 0.05$ ) slopes than all other animals and the toads were lower than rats and trout for $\mathrm{VO}_{2}$ versus SCc, SDH and NADHOX. Activities for $\mathrm{VO}_{2}$ versus $\mathrm{SDH}$ and $\mathrm{NADHOX}$ from mammals and fish were not significantly different. 


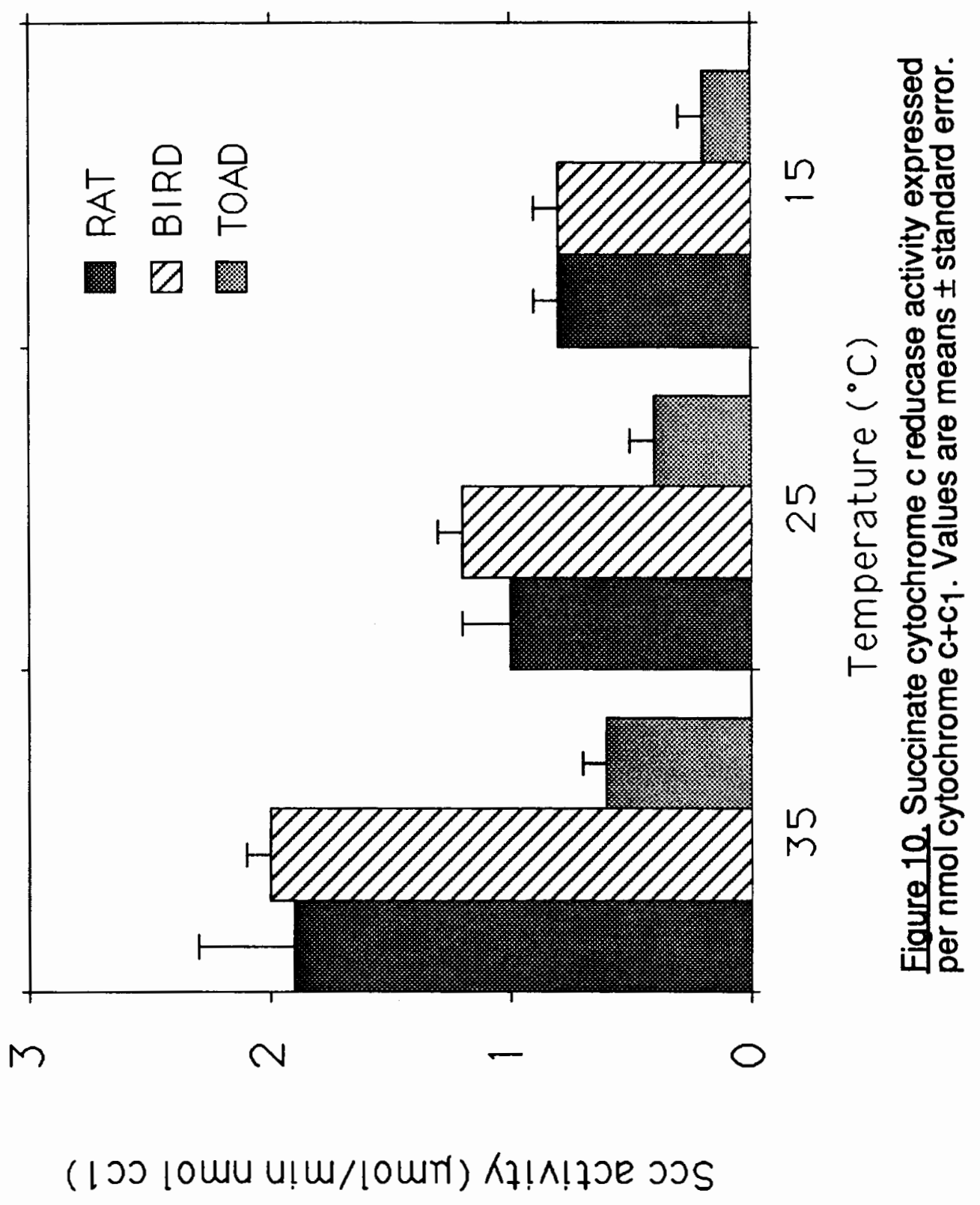




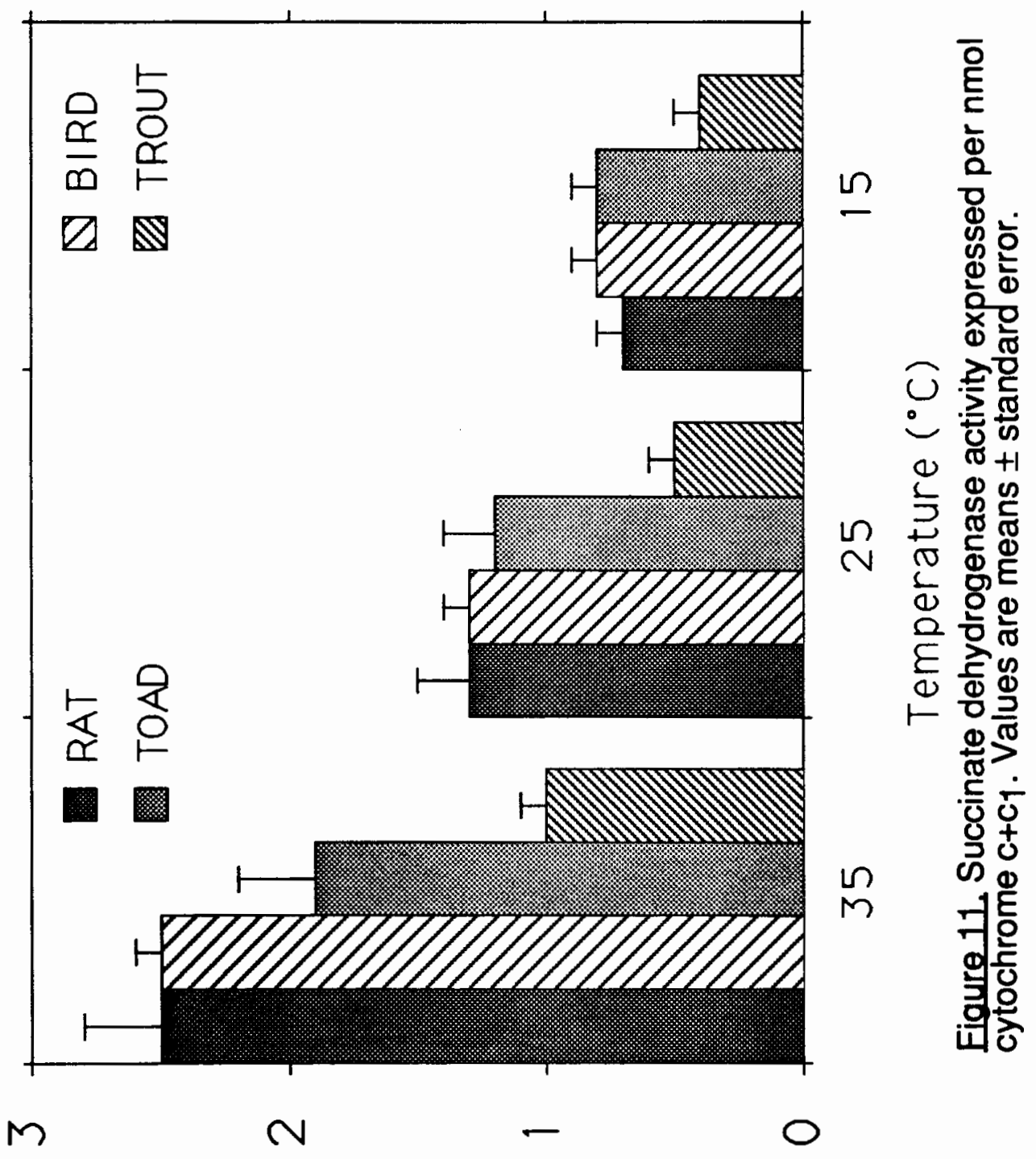

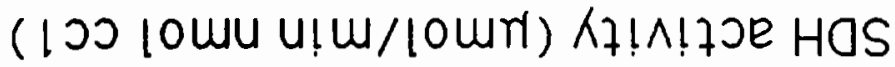




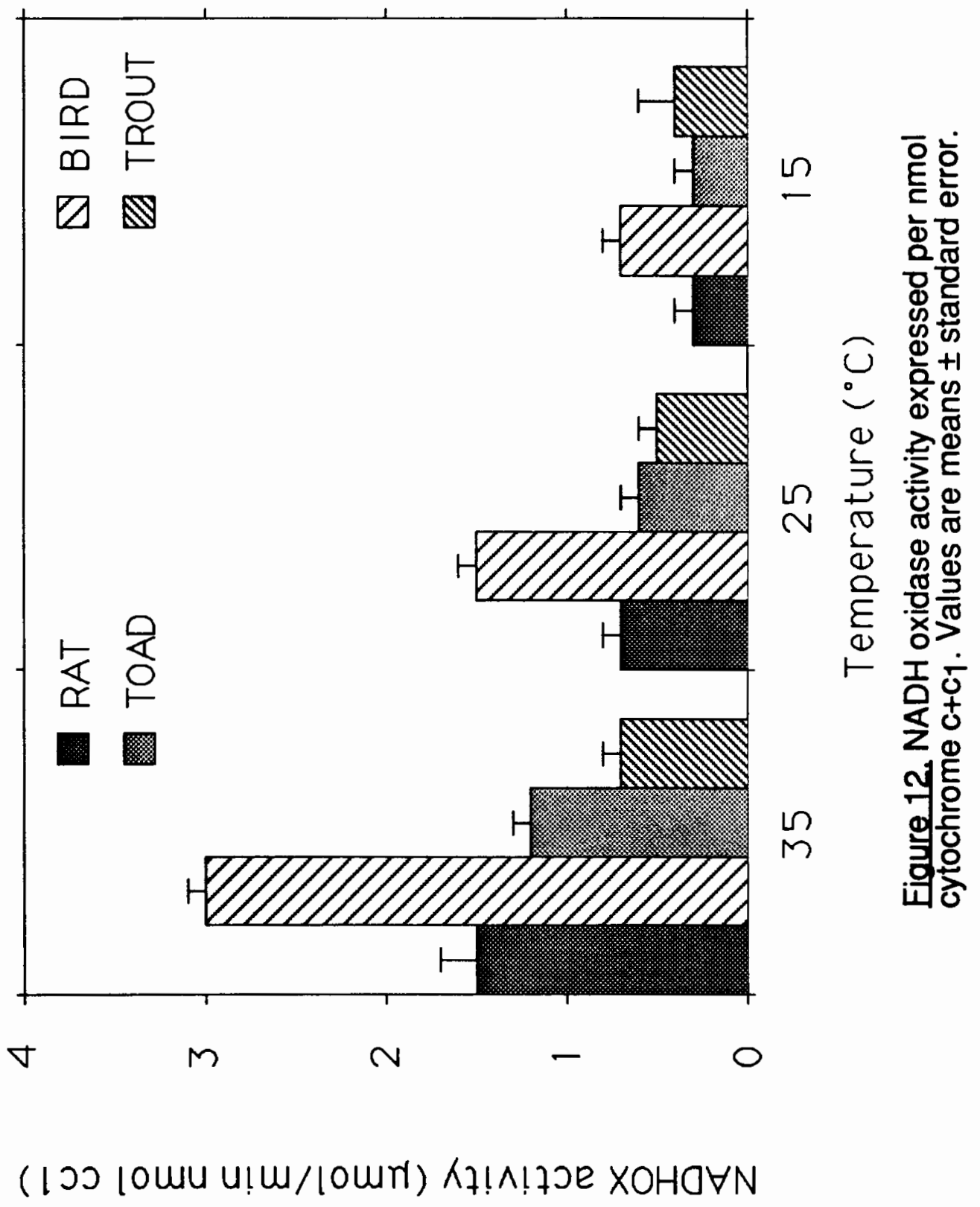




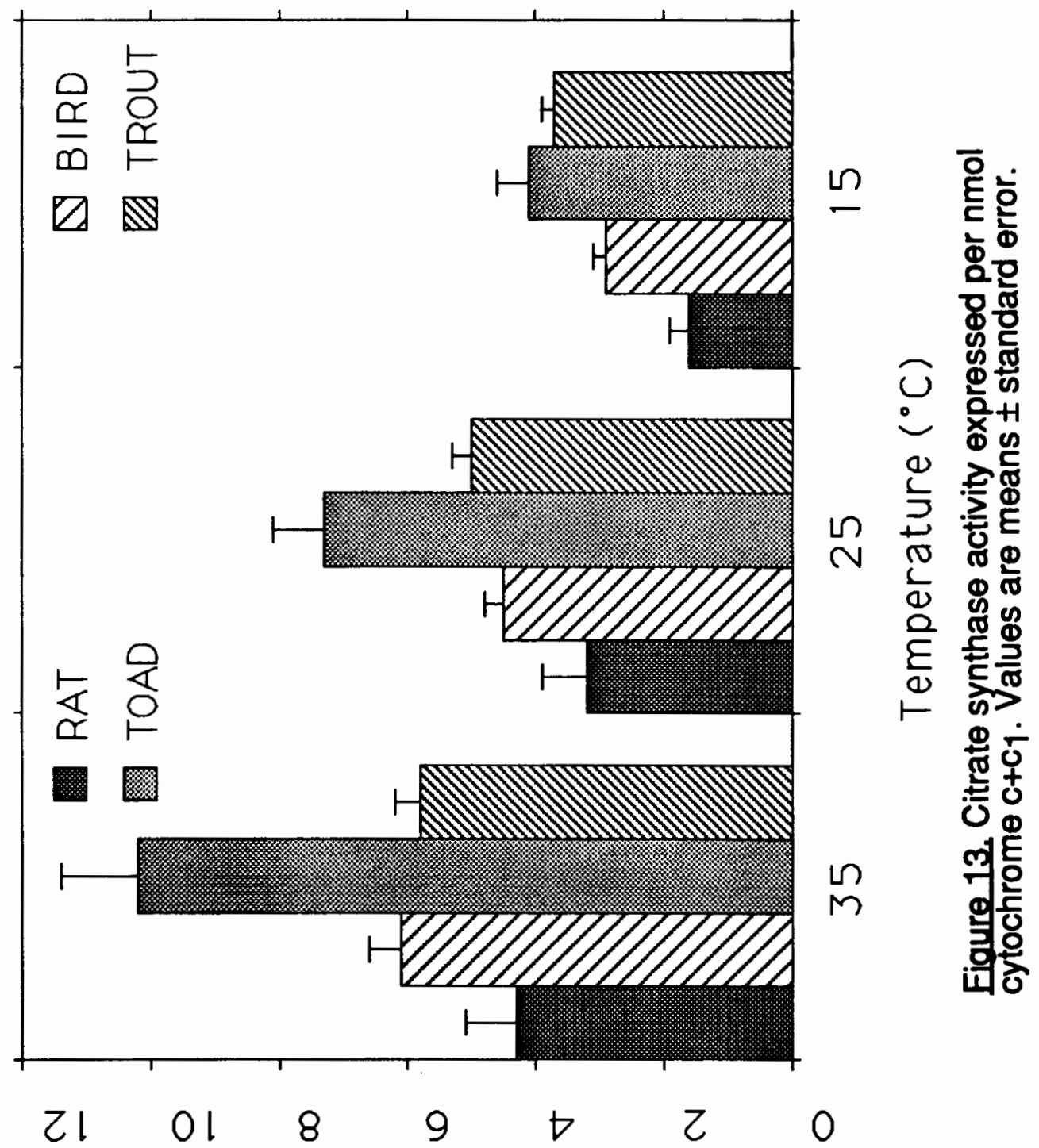

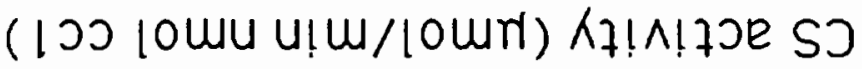




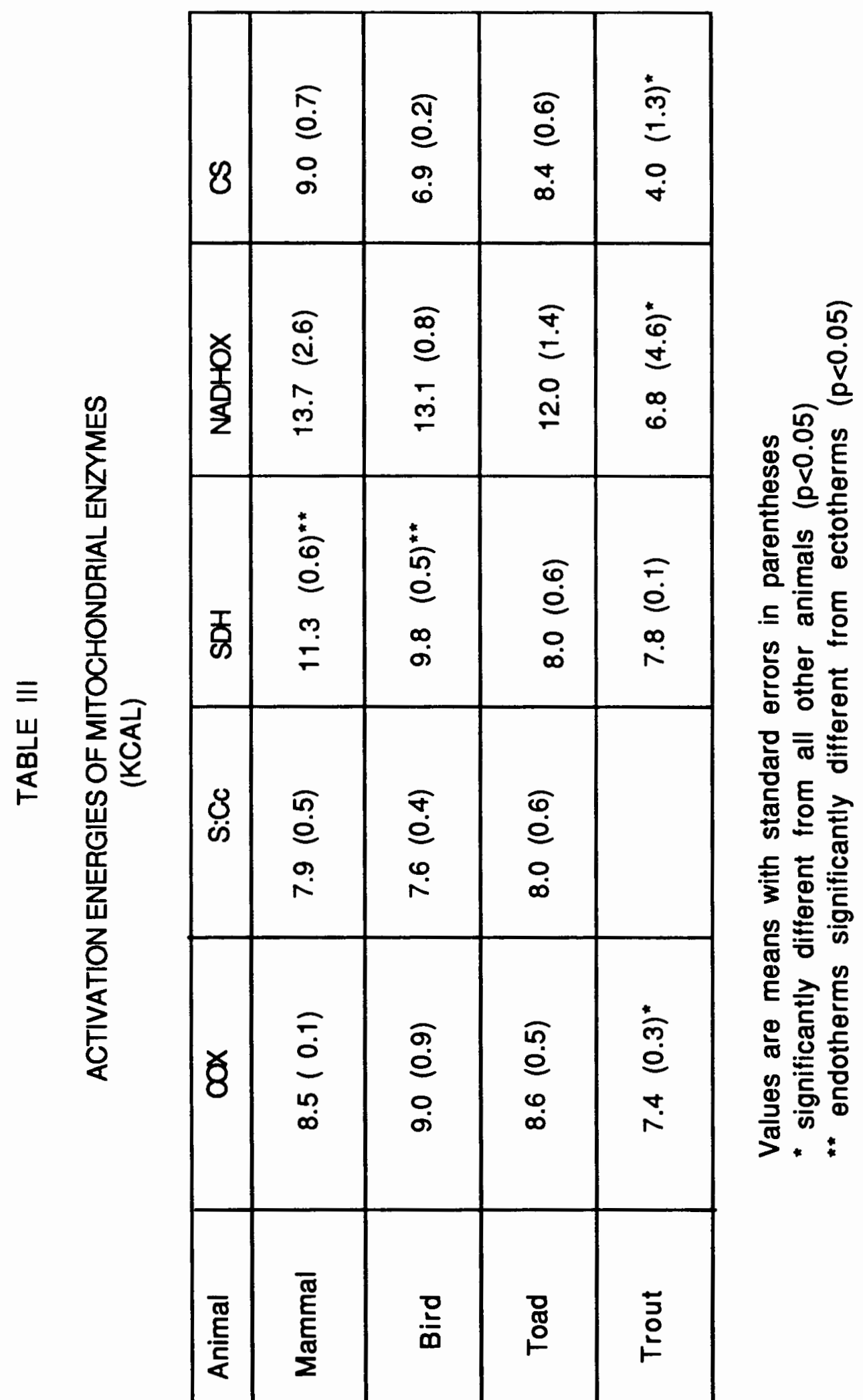

39 
TABLE IV

MITOCHONDRIAL ENZYME AND VO2 ACTIVITY RATIOS

\begin{tabular}{|c|l|l|l|l|l|}
\hline Ratio & Temp & Mammal & Bird & Toad & Fish \\
\hline \multirow{3}{*}{ VOR/COX } & 35 & 4.6 & 0.7 & 1.3 & 1.4 \\
& 25 & 3.1 & 0.6 & 1.0 & 1.5 \\
& 15 & 1.1 & 0.9 & 0.7 & 1.1 \\
\hline \multirow{2}{*}{ VO2/SDH } & 35 & 21.4 & 3.9 & 7.8 & 25.4 \\
& 25 & 17.4 & 3.1 & 6.0 & 39.1 \\
& 15 & 7.8 & 1.3 & 3.9 & 21.1 \\
\hline \multirow{2}{*}{ VO2/CS } & 35 & 14.4 & 1.6 & 1.4 & 4.5 \\
& 25 & 7.7 & 1.0 & 1.0 & 4.1 \\
& 15 & 3.6 & 0.4 & 0.8 & 2.3 \\
\hline \multirow{3}{*}{ VO2NADHOX } & 35 & 38.8 & 3.2 & 11.8 & 37.1 \\
& 25 & 33.9 & 2.7 & 11.3 & 47.0 \\
& 15 & 16.7 & 1.4 & 10.6 & 21.9 \\
\hline \multirow{2}{*}{ SDHCOX } & 35 & 19.8 & 18.8 & 17.2 & 5.5 \\
& 25 & 17.8 & 17.3 & 17.1 & 3.84 \\
& 15 & 14.4 & 14.9 & 18.6 & 5.2 \\
\hline & 35 & 32.4 & 45.2 & 94.3 & 31.2 \\
CSICOX & 25 & 44.4 & 56.1 & 103.6 & 36.7 \\
& 15 & 31.6 & 54.2 & 96.4 & 47.1 \\
\hline \multirow{3}{*}{ NADHOXCOX } & 35 & 12.0 & 22.7 & 11.3. & 3.8 \\
& 25 & 9.1 & 20.3 & 8.9 & 3.2 \\
& 15 & 6.8 & 14.2 & 6.8 & 5.1 \\
\hline \multirow{2}{*}{ SDHCS } & 35 & 61.5 & 41.6 & 18.3 & 17.5 \\
& 25 & 44.3 & 30.9 & 16.4 & 10.5 \\
& 15 & 46.1 & 27.5 & 19.4 & 11.1 \\
\hline \multirow{2}{*}{ NADHOXSOH } & 35 & 60.2 & 120.6 & 65.5 & 68.5 \\
& 25 & 51.4 & 117.1 & 52.6 & 83.4 \\
& 15 & 46.9 & 95.4 & 36.7 & 96.8 \\
\hline \multirow{2}{*}{ NADHOXCS } & 35 & 37.0 & 50.1 & 12.0 & 12.0 \\
& 25 & 22.8 & 34.1 & 8.6 & 8.7 \\
& 15 & 21.7 & 26.2 & 7.1 & 10.7 \\
\hline & & & & & \\
\hline
\end{tabular}




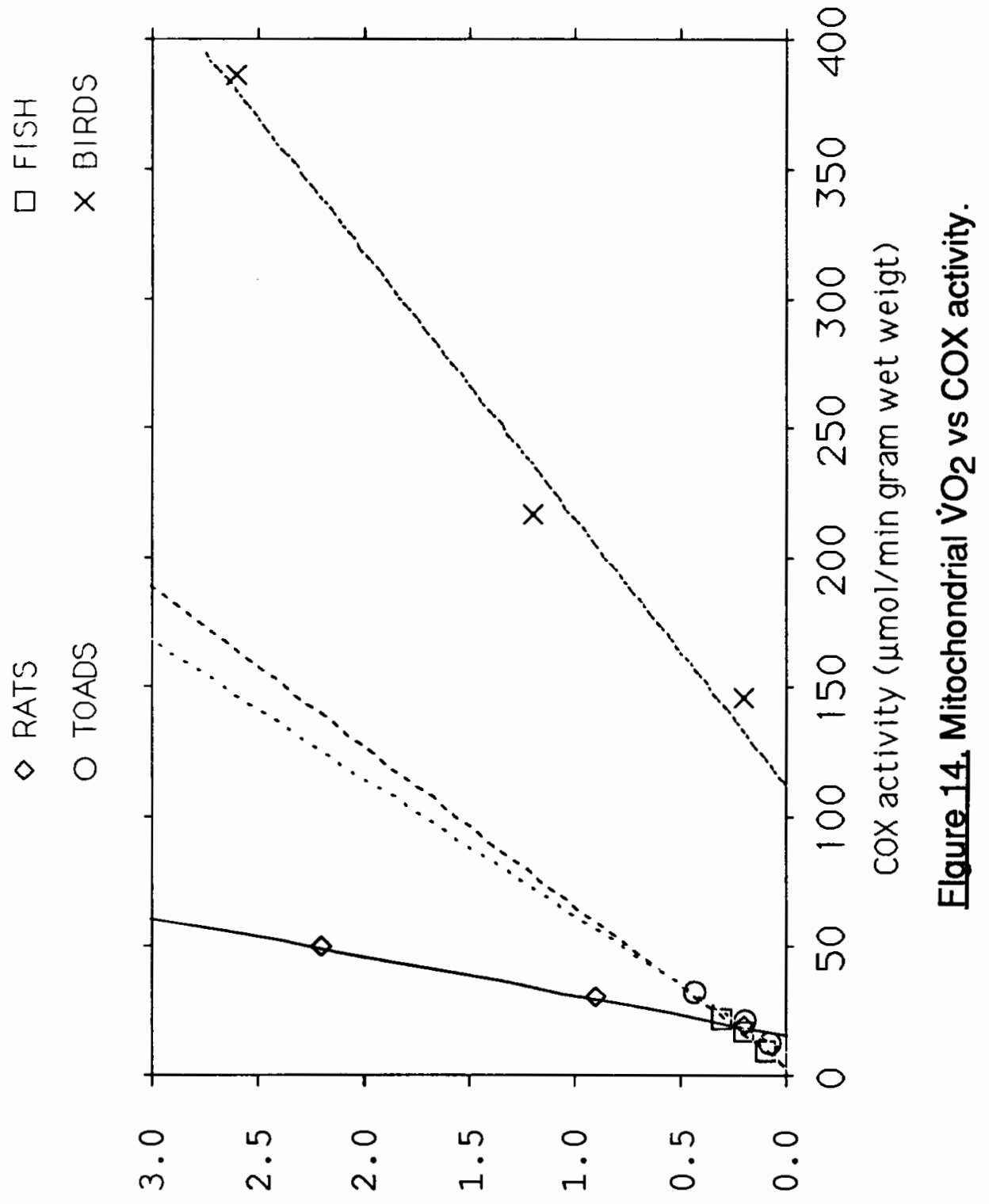

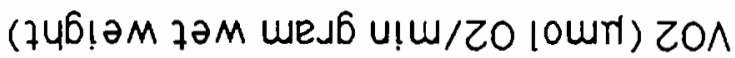




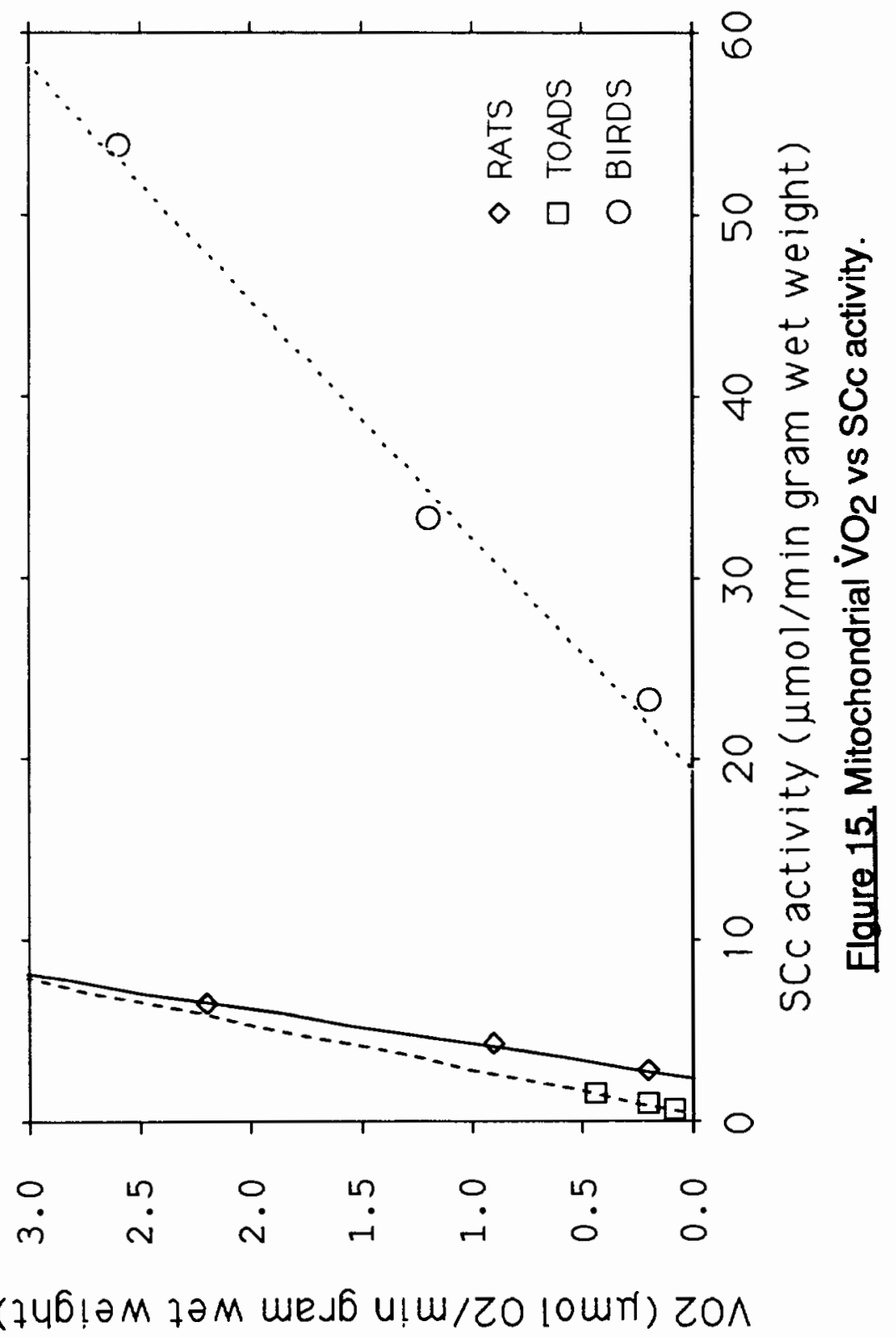




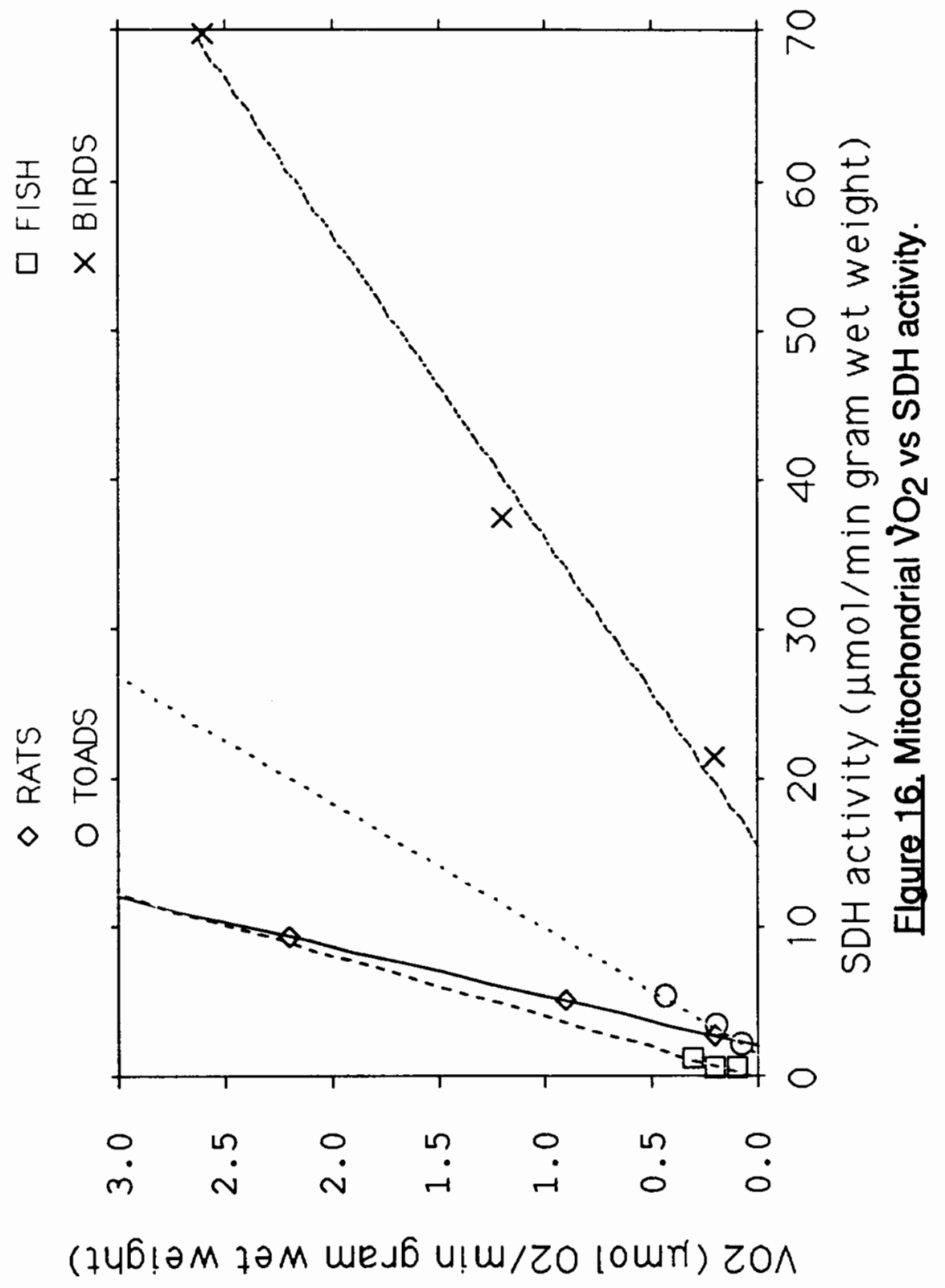




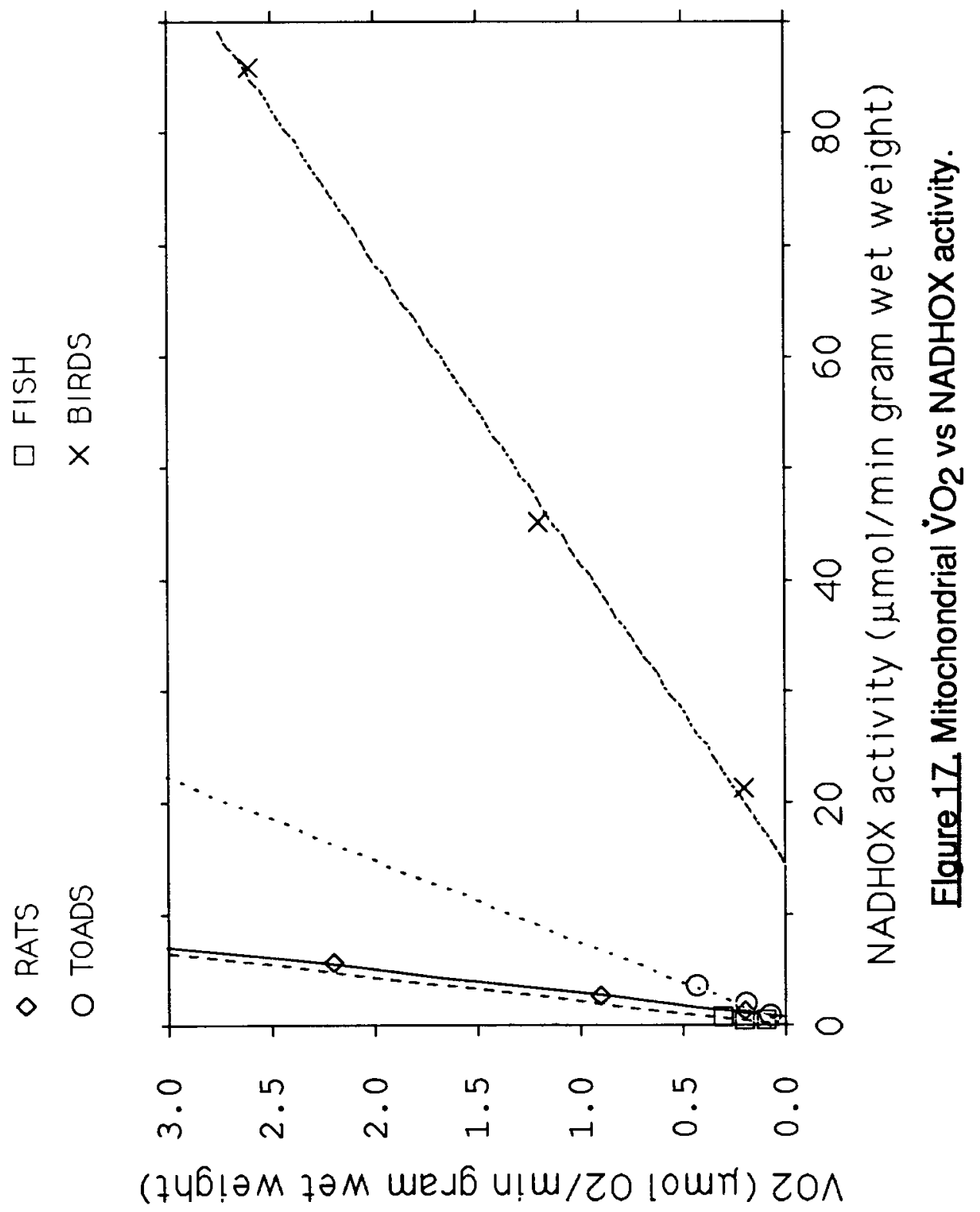




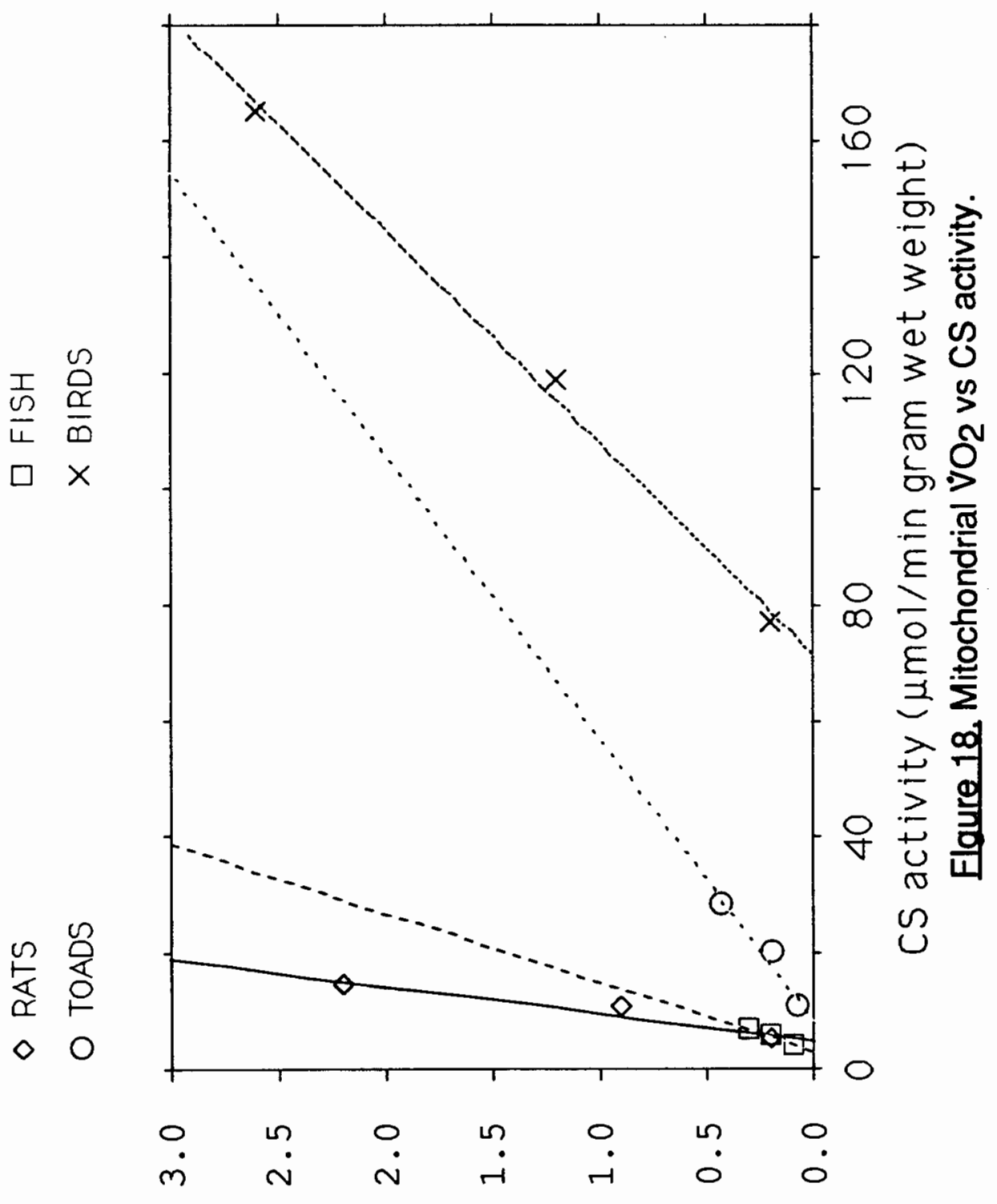

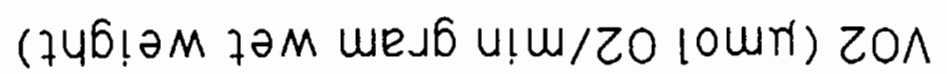




\section{DISCUSSION}

One purpose of this study was to test the hypothesis, proposed by Hoppeler and Lindstedt (1985), that the determinant of organismal $\mathrm{VO}_{2}$ max is a cellular limit to oxygen utilization by skeletal muscle mitochondria. Jones (1984) has shown that mitochondrial clustering can significantly limit mitochondrial respiration by reducing the oxygen concentration of the environment surrounding the mitochondrion. Since skeletal muscle mitochondria are very densely clustered around capillaries it is possible that oxygen availability, and not mitochondrial oxidation rate, may be the critical limit to aerobic energy production. The test of this hypothesis was to purify mitochondria from the muscle tissue and measure mitochondrial $\mathrm{VO}_{2}$ in an environment which is not oxygen-limited. By knowing what percentage of the total mitochondrial population was measured, an estimate of the aerobic potential ( $\mathrm{ml} \mathrm{O}_{2} /$ gram hour) of muscle tissue can be made. If the limit to $\mathrm{VO}_{2}$ max is at the cellular level, the aerobic potential of the muscle, calculated from measurements on the isolated mitochondria, should correspond with figures for whole animal $\mathrm{VO}_{2} \max$. If the limit is oxygen availability, however, the calculated aerobic potential should exceed $\dot{\mathrm{V}}_{2}$ max. The analysis is based on the 
following assumption: $90 \%$ of $\mathfrak{V O}_{2}$ max is oxygen consumed by skeletal muscle taking up approximately $45 \%$ of body mass (Weibel, 1979; Hoppeler and Lindstedt, 1985). This calculation would tend to underestimate $\mathrm{VO}_{2}$ max in animals with less than $45 \%$ muscle mass (toads) and overestimate $\mathrm{V}_{2}$ max in animals with greater than $45 \%$ muscle mass (trout). My data show mitochondrial $\mathrm{VO}_{2}$ per gram body weight to be in excess of the published values for organismal $\mathrm{VO}_{2} \max ($ Table I). Since core temperature during activity is greater than $35^{\circ} \mathrm{C}$ for birds and mammals, these figures can be considered an underestimate of the mitochondrial aerobic potential for endotherms. This potential is still 1.5 to 3 times larger than the published values for organismal ${ }^{\circ} \mathrm{O}_{2}$ max expressed per gram body mass. This finding indicates that estimates of ${ }^{\mathrm{VO}_{2}}$ max based on mitochondrial number from morphometric analysis of tissue samples may be in error because the assumption is made that all mitochondria are functioning maximally at organismal $\mathrm{VO}_{2} \max$ (Hoppeler and Lindstedt, 1985). My in vitro results suggest that all mitochondria in vivo are not functioning at organismal $\mathrm{VO}_{2}$ max. Jones (1984) has determined the oxygen tension necessary for the half-maximal rate of cytochrome $\mathrm{c}$ reoxidation, a measure of oxidative activity in mitochondria, to be about 0.1 torr. This value is well below the average physiological tissue oxygen tension of approximately 40 torr ( Jones, 1984). Thus, mitochondria respire 
maximally at very low oxygen concentrations, and mitochondrial $\mathrm{V}_{2}$ can be considered to show an all-or-none response under normal physiological conditions. In addition, this data brings into question the mitochondrial $\mathrm{VO}_{2}$ value of $3-5 \mathrm{ml} / \mathrm{min} \cdot \mathrm{ml}$ mitochondrial volume calculated from organismal $\mathrm{VO}_{2}$ max data and estimates of total organismal mitochondrial number by Hoppeler and Lindstedt (1985). This does not represent the maximum potential mitochondrial $\mathrm{VO}_{2}$ based on the present in vitro measurements.

With decreasing temperature, mitochondria from the endothermic organisms had a significantly greater decrease in respiration when compared with the ectothermic organisms ( Table I). The seven-fold higher mitochondrial $\mathrm{VO}_{2}$ per gram muscle of the endotherms at $35^{\circ} \mathrm{C}$ decreases significantly at $15^{\circ} \mathrm{C}$, but is still two times higher than that for the the ectotherms. This agrees with earlier comparisons of mitochondrial oxidation ( Lyons and Raison, 1970; Raison, et. al., 1971a,b; Hazel, 1972a,b; Roberts, et. al. 1972; Raison and McMurchie, 1974; Wodtke, 1976) which showed significantly greater decreases in rate with decreasing temperature in endotherms compared to ectotherms. The $Q_{10}$ values for mitochondrial $\mathrm{VO}_{2}$ were significantly higher in the endotherms than in the ectotherms but comparable to previously published values for both groups (Roberts, et al, 1972; Pye, 1973). In practical terms, the 
temperature at which a $\mathrm{VO}_{2}$ measurement is made can be of critical importance to an accurate measure of an organism's physiological state. It cannot be assumed that an ectotherm studied at $25^{\circ} \mathrm{C}$ can be compared with an endotherm studied at the same temperature, or that differences in organismal $\mathrm{VO}_{2}$ max between endotherms and ectotherms can be explained on the basis of $Q_{10}$.

Arrhenius plots of mitochondrial $\mathrm{VO}_{2}$ differ significantly between groups, though the experimental protocol did not enable a precise determination of transition temperature. Throughout the temperature range, endotherms have significantly higher activation energies for mitochondrial $\dot{\mathrm{VO}}_{2}$ than do ectotherms. Therefore, the energy required to activate mitochondrial $\dot{\mathrm{VO}}_{2}$ is greater in endotherms than in ectotherms. Raison and co-workers ( Lyons and Raison, 1970; Kumamoto, et al, 1971; Raison, et. al., 1971a,b; Lyons, et. al., 1974; Raison and McMurchie, 1974; McMurchie and Raison, 1979 ) have related this difference, through spin labeling and polarographic studies, to phase changes in the phospholipid portion of the mitochondrial inner membrane. At temperatures below $23^{\circ} \mathrm{C}$ the lipids in the mammalian mitochondrial inner membrane undergo a phase transition and the membrane becomes less fluid (Kumamoto, et al, 1971). This reduces diffusion rates of membrane-soluble compounds, such as ubiquinone, and may possibly increase the energy 
required by allosteric enzymes to undergo the conformational changes associated with function (Kumamoto, et al, 1971; Raison, et. al., 1971a; McMurchie and Raison, 1979). Wodtke (1976, 1978,1981) and Ohira and Ohira (1988) have shown that acclimation temperature can influence both the lipid composition and transition temperature of ectotherm inner mitochondrial membranes. Other studies (Roberts, et al., 1972; Geiser et al., 1984; Raison, et. al., 1988) have shown similar changes in the composition of mitochondrial membranes of hibernating mammals, while cold acclimation had no effect on the mitochondrial membranes of non-hibernating mammals. Lyons and Raison (1970) found no difference in the temperature response of mitochondrial oxidation between warm and cold acclimated fish. My data agree with earlier comparisons of mitochondrial oxidation and $\mathrm{V}_{2}$ activation energies between endotherms and ectotherms (Lyons and Raison, 1970; Raison, et. al., 1971a,b; Roberts, et. al., 1972; Pye, 1973; Lyons, et. al., 1974; Raison and McMurchie, 1974; Pye, et. al., 1976; McMurchie and Raison, 1978; Wodtke, $1973,1974,1976,1978,1981)$ ). It is interesting to note that the high $\mathrm{E}_{\mathrm{a}}$ for mitochondrial $\mathrm{VO}_{2}$ found in all animals is not reflected in $E_{a}$ values for most of the the individually assayed enzymes. In the toads, there was no significant difference in $\mathrm{E}_{\mathrm{a}}$ between NADHOX and mitochondrial $\mathrm{VO}_{2}$. This difference in $\mathrm{E}_{\mathrm{a}}$ between mitochondrial $\mathrm{VO}_{2}$ and enzyme activity 
may result from the presence of detergent in all enzyme assays except NADHOX, where membranes were disrupted by sonication rather than detergent treatment. This suggests that modification of membrane integrity by the addition of detergents or sonic disruption alters the thermal responses of the enzyme complexes. Previous studies (Raison, et.al., 1971a; McMurchie and Raison, 1979) have shown that temperature induced phase changes in mitochondrial membranes, indicated by breaks in Arrhenius plots of mitochondrial oxidation and enzyme activity, could be removed in the presence of detergents. This suggests that it is the membrane environment surrounding the enzyme complexes, and not the complexes themselves, that is temperature sensitive. The matrix enzyme CS, which is not influenced by membrane changes, was lower in trout compared to all other animals. In all animals tested, however, the $E_{a}$ for CS was lower than for $\mathrm{VO}_{2}$.

Temperature dependent changes in $\mathrm{VO}_{2}$ and enzyme activity per nmole cytochrome $c+c_{1}$ vary significantly but without relation to endothermic or ectothermic groups. Values expressed per nmole cytochrome $c+c_{1}$, based on direct spectrophotometric measurements of mitochondrial cytochromes $\mathrm{C}_{+} \mathrm{c}_{1}$, are intended to quantitate individual mitochondrial characteristics with respect to concentration of an intrinsic component of the mitochondrial inner 
membrane. This is necessary because mitochondrial preparations from skeletal muscle contain varying amounts of non-mitochondrial protein which are not distinguishable from mitochondrial protein using standard protein assay techniques. In addition, activities expressed per gram wet weight tissue often obscure species specific differences in mitochondria. This is important in light of the very low $\mathrm{VO}_{2}$ per nmole $\mathrm{C}+\mathrm{C}_{1}$ for bird mitochondria compared to mammal mitochondria even though the two are very similar on a per gram muscle basis. Amphibians and fish represent a similar case in point: $\mathrm{VO}_{2}$ per nmole cytochrome $\mathrm{C}+\mathrm{c}_{1}$ is substantially higher in fish than in amphibians. Enzyme activities expressed in the same units (Table Ilb) show no definite pattern uniting all mitochondria. Each vertebrate class has its own mitochondrial enzyme profile and characteristic responses to temperature.

Ratios of mitochondrial enzyme activity were compared to determine if there were common relationships between animals not represented by absolute activities (Table IV). While the ratios of NADHOX to CS, SDH to COX, CS to COX and SDH to CS activity were significantly higher in endotherms compared to ectotherms, there were no cases where ratios were the same between species within a group. In particular, while the ratio of SDH to COX differed significantly between endotherms and ectotherms, mammals, birds 
and amphibians were not significantly different. The remaining activity ratios show no apparent relationship to vertebrate class or endothermic or ectothermic group. Of note is the three-fold greater ratio of CS to COX in amphibians and the two-fold greater ratio of NADHOX to SDH in birds compared to the other animals. 


\section{CONCLUSIONS}

The above data indicate that mitochondria are different in species representing four vertebrate classes. Raison, et. al. (1988) have shown that mitochondria have tissue specific properties in a hibernation adapted mammal and Roberts, et. al. (1972) have shown species specific differences in mitochondrial succinoxidase (ETS complexes II,III and IV) activity between hibernating and non-hibernating mammals. Since differences in mitochondrial physiology can be found within species belonging to the same vertebrate class, differences in mitochondrial physiology between classes are not unexpected. While the present study is limited by the number of species studied, it is clear that all vertebrate muscle mitochondria are not the same. This conclusion strongly speaks to the need for great care in comparative analyses based on single animal studies. Additionally, enzymatic measures intended to estimate aerobic capacity are not applicable across taxonomic lines. While analyses of cellular and organismal $\mathrm{VO}_{2}$ based solely on mitochondrial numbers are important to our understanding of aerobic physiology, they may lead to incorrect conclusions due to lack of attention to mitochondrial variation. My data show that mitochondria in vitro are able to respire at rates much higher than 
are estimated from measures of organismal $\mathrm{VO}_{2}$ max. This indicates, therefore, that the limit to organismal $\mathrm{VO}_{2}$ max must lie somewhere other than in the mitochondrion. It is apparent that more effort is needed to characterize mitochondrial physiology and biochemistry for a wide range of experimental animals. 


\section{LITERATURE CITED}

Alp, P.R., E.A. Newsholme, V.A. Zammit (1976). Activities of citrate synthase and NAD+-linked and NADP-linked isocitrate dehydrogenase in muscle from vertebrates and invertebrates. Biochemical Journal 154: 689-700.

Anderson, P.M. (1986). Effects of trimethylamine oxide, and osmolality on respiration and citrulline synthesis by isolated hepatic mitochondria from Squalus acanthias. Comparative Biochemistry and Physiology. 85B: 783-788.

Blomqvist, C.G. and B. Saltin (1983). Cardiovascular adaptations to physical training. Annual Review of Physiology. 45: 169-189.

Bookelman, H., J.M.F. Trijbels, R.C.A. Sengers, A.J.M. Janssen (1978). Measurement of cytochromes in human skeletal muscle mitochondria, isolated from fresh and frozen stored muscle specimens. Biochemical Medicine 19: 366-373.

Brett, J.R. and T.D.D. Groves (1979). Physiological Energetics. In: Fish Physiology, v.7; Bioenergetics and Growth. Hoar, W.S., D.J. Randall, J.R. Brett. ed., Academic Press, New York,N.Y. pp279-352.

Butler, P.J. N.H. West, D.R. Jones (1977). Respiratory and cardiovascular responses of the pigeon to sustained, level flight in a wind tunnel. Journal of Experimental Biology. 71: 7-26.

Chance, B. and G. R. Williams (1959). The respiratory chain and oxidative phosphorylation. Advances in Enzymology. 17: 65-134

Chappell, J.B. (1964). The oxidation of citrate, isocitrate and cis-aconitate by isolated mitochondria. Biochemical Journal. 90: 225-237.

Darley-Usmar, V.M., N.G. Kennaway, N.R.M. Buist, R.A. Capaldi (1983). Deficiency in ubiquinone cytochrome $c$ reductase in a patient with mitochondrial myopathy and lactic acidosis. Proceedings of the National Academy of Science, USA. 80: 5103-5106. 
Davies, K.J.A., L. Packer, G.A. Brooks (1981). Biochemical adaptation of mitochondria, muscle, and whole-animal respiration to endurance training. Archives of Biochemistry and Biophysics.209: 539-544.

Di Prampero, P.E. (1985). Metabolic and circulatory limits to $\mathrm{VO}_{2} \max$ at the whole animal level. Journal of Experimental Biology. 115 : 319-331.

Driedzic, W.R., B.D. Sidell, D. Stowe, R. Branscombe (1987). Matching of vertebrate cardiac energy demand to energy metabolism. American Journal of Physiology. 252: R930-R937.

Fischer, J.C., W. Ruitenbeek, A.M. Stadhouders, J.M. Trijbels, R.C.A. Sengers, A.J.M. Janssen (1985a). Investigation of mitochondrial metabolism in small human skeletal muscle biopsy specimens. Improvement of preparation procedure. Clinica Chimica Acta. 145: 89-99.

Fischer, J.C., W. Ruitenbeek, J.A. Berden, J.M. Trijbels, J.H. Veerkamp, A.M. Stadhouders, R.C.A. Sengers, A.J.M. Janssen (1985b). Differential investigation of the capacity of succinate oxidation in human skeletal muscle. Clinica Chimica Acta. 153: 23-26.

Fischer, J.C., W. Ruitenbeek, J.M. Trijbels, A.M. Stadhouders, R.C.A.Sengers, A.J.M. Janssen (1986). Estimation of NADH oxidation in human skeletal muscle mitochondria. Clinica Chimica Acta. 153: 263-273.

Geiser, F., M.L. Augee, J.K. Raison (1984). Thermal response of liver mitochondrial membranes of the heterothermic bat (Miniopterus schreibersii) in summer and winter. Journal of Thermal Biology. 9:183-188.

Hazel, J.R. (1972a). The effect of temperature acclimation upon succinic dehydrogenase activity from the epaxial muscle of the common goldfish (Carassius auaratus L.)-I. Properties of the enzyme and the effect of lipid extraction. Comparative Biochemistry and Physiology. 43B: 837-861.

Hazel, J.R. (1972b). The effect of temperature acclimation upon succinic dehydrogenase activity from the epaxial muscle of the common goldfish ( Carassius auratus L.) -ll. Lipid reactivation of the soluble enzyme. Comparative Biochemistry and Physiology. 43B: 863-882. 
Hedrick, M.S. (1985). Aspects of cardiovascular oxygen transport in vertebrates. Master's Thesis (unpublished), Portland State University, Portland, OR.

Hillman, S.S. (1976). Cardiovascular correlates of maximal oxygen consumption rates in anuran amphibians. Journal of Comparative Physiology. 109: 199-207.

Hillman, S.S. (1980). The effect of anemia on metabolic performance in the frog, Rana pipiens.. Journal of Experimental Zoology. 211: 107-111.

Hillman, S.S. (1982). Effects of DL-propranolol on exercise heart rate and maximal rates of oxygen consumption in Scaphiopus intermontanus. Experientia. 38: 940-941.

Hillman, S.S., P.C. Withers, M.S. Hedrick, P.B. Kimmel (1985). The effects of erythrocythemia on blood viscosity, maximal systemic oxygen transport and maximal rates of oxygen consumption in an amphibian. Journal of Comparative Physiology. 155B: 577-581.

Holloszy, J.O. and F.W. Booth (1976). Biochemical adaptations to endurance exercise in muscle. Annual Review of Physiology. 38: 273-291.

Hoppeler, H., O. Mathieu, R. Krauer, H. Claassen, R.B. Armstrong, E.R. Weibel (1981a). Design of the mammalian respiratory system. VI. Distribution of mitochondria and capillaries in various muscles. Respiration Physiology. 44: 87-111.

Hoppeler, H., O. Mathieu, E.R. Weibel, R. Kraver, S.L. Lindstedt, C.R.

Taylor (1981b). Design of the mammalian respiratory system.

VIII. Capillaries in skeletal muscle. Respiration Physiology. 44:

129-150.

Hoppeler, H. and S.L. Lindstedt (1985). Malleability of skeletal muscle in overcoming limitations: structural elements. Journal of Experimental Biology. 115: 355-364.

Hoppeler, H., S.R. Kayar, H. Claassen, E. Uhlmann, R.H. Karas (1987). Adaptive variation in the mammalian respiratory system in relation to energetic demand: III. Skeletal muscles: setting the demand for oxygen. Respiration Physiology. 69: 27-46. 
Hoppeler, H. and S.R. Kayar (1988). Capillarity and oxidative capacity of muscles. News in Physiological Sciences. 3: 113-116.

Hudlicka, O., A.J.A. Wright, H. Hoppeler, E. Uhlmann (1988). The effect of chronic bradycardial pacing on the oxidative capacity in rabbit hearts. Respiration Physiology. 72: 1-12.

Jones, D.P. (1984). Effect of clustering on $\mathrm{O}_{2}$ supply in hepatocytes. American Journal of Physiology. 247: C83-C89.

Karas, R.H., C.R. Taylor, K. Rosler, H. Hoppeler (1987). Adaptive variation in the mammalian respiratory system in relation to energetic demand: $V$. Limits to oxygen transport by the circulation. Respiration Physiology. 69: 65-79.

Kumamoto, J., J.K. Raison, J.M. Lyons (1971). Temperature "breaks" in Arrhenius plots: a thermodynamic consequence of a phase change. Journal of Theoretical Biology. 31: 47-51.

Lowry, O.H., N.J. Rosebrough, A.L. Farr, R.J. Randall (1951). Protein measurement with the folin phenol reagent. Journal of Biological Chemistry. 198: 265-275.

Lyons, J.M. and J.K. Raison (1970). A temperature-induced transition in mitochondrial oxidation: contrasts between cold and warm-blooded animals. Comparative Biochemistry and Physiology. 37: 405-411.

Lyons, J.M., J.K. Raison, J. Kumamoto (1974). Polarographic determination of phase changes in mitochondrial membranes in response to temperature. Methods in Enzymology. 32: 258-262.

Marsh, R.L. and T.L. Taigen (1987). Properties enhancing aerobic capacity of calling muscles in gray tree frogs Hyla versicolor. American Journal of Physiology. 252: R786-R793.

Mathieu, O., R. Krauer, H. Hoppeler, P. Gehr, S.L. Lindstedt, R.McN. Alexander, C.R. Taylor, E.R. Weibel (1981). Design of the mammalian respiratory system. VII. Scaling mitochondrial volume in skeletal muscle to body mass. Respiration Physiology. 44:113-128.

McMurchie, E.J. and J.K. Raison (1979). Membrane fluidity and its effect on the activation energy of membrane-associated enzymes. Biochimica et Biophysica Acta. 554: 364-374. 
Ohira,M. and Y. Ohira (1988). Effects of exposure to cold on metabolic rate characteristics in gastrocnemius muscle of frog (Rana pipiens). Journal of Physiology (London). 395: 589-595.

Peterson, G.L. (1977). A simplification of the protein assay method of Lowry et al. which is more generally applicable. Analytical Biochemistry. 83: 346-356.

Putnam, R.W. and A. F. Bennett (1983) Histochemical, enzymatic and contractile properties of skeletal muscles of three anuran amphibians. American Journal of Physiology. 244: R558-R567.

Pye, V.I. (1973). Acute temperature changes and the oxidation rates of ectotherm mitochondria. In: Effects of Temperature on Ectothermic Organisms: Ecological Implications and Mechanisms of Compensation. W. Wieser, ed. Springer, Berlin.

Pye, V.I., W. Wieser, M. Zech (1976). The effect of season and experimental temperature on the rates of oxidative phosphorylation of liver and muscle mitochondria from the tench, Tinca tinca.. Comparative Biochemistry and Physiology. 54B: 13-20.

Raison, J.K., J.M. Lyons, W.W. Thomson (1971a). The influence of membranes on the temperature-induced changes in the kinetics of some respiratory enzymes of mitochondria. Archives of Biochemistry and Biophysics. 142: 83-90.

Raison, J.K., J.M. Lyons, R.J. Melhorn, A.D. Keith (1971b). Temperature-induced phase changes in mitochondrial membranes detected by spin-labeling. Journal of Biological Chemistry. 246: 4036-4040.

Raison, J.K. and E.J. McMurchie (1974). Two temperature-induced changes in mitochondrial membranes detected by spin-labelling and enzyme kinetics. Biochimica et Biophysica Acta. 363: $135-140$.

Raison, J.K., M.L. Augee, R.C. Aloia (1988). Mitochondrial membrane transitions in heart and different organs of a hibernator. American Journal of Physiology. E378-E383. 
Roberts, J.C., R.M. Arine, R.H. Rochelle, R.R.J. Chaffee (1972). Effects of temperature on oxidative phosphorylation of liver mitochondria from hamster, rat and squirrel monkey.

Comparative Biochemistry and Physiology. 41B: 127-135

Saltin, B. (1985). Malleability of the system in overcoming limitations: functional elements. Journal of Experimental Biology. 115: 345-354.

Schultz, A.R. (1988). Energy metabolism in the whole animal revisited. Respiration Physiology. 73: 11-20.

Singer,T.P. (1974) Determination of the activity of succinate, NADH, choline and $\alpha$-glycerophosphate dehydrogenases. In: Glick, D., ed. Methods of Biochemical Analysis, Vol. 22. New York: Interscience. p123-175.

Smith,C.L. (1973a). Thermostability of some mitochondrial enzymes of lower vertebrates-I. General survey. Comparative Biochemistry and Physiology. 44B: 779-788.

Smith,C.L. (1973b). Thermostability of some mitochondrial enzymes of lower vertebrates-II. Fresh-water teleosts. Comparative Biochemistry and Physiology. 44B: 789-801.

Smith, C.L. (1973c). The temperature dependence of oxidative phosphorylation and of the activity of various enzyme systems in liver mitochondria from cold- and warm-blooded animals. Comparative Biochemistry and Physiology. 46B: 445-461.

Srere, P.A. (1969). Citrate Synthase. Methods in Enzymology. 13: 3-5.

Taylor, C.R. and E.R. Weibel (1981). Design of the mammalian respiratory system. I. Problem and strategy. Respiration Physiology. 44: 1-10.

Taylor, C.R., G.M.O. Maloiy, E.R. Weibel, V.A. Langman, J.M.Z. Kamau, H.J. Seeherman, N.C. Heglund (1981). Design of the mammalian respiratory system. III. Scaling maximum aerobic capacity to body mass: wild and domestic mammals. Respiration Physiology. 44: 25-37.

Taylor, C.R., R.H. Karas, E.R. Weibel, H. Hoppeler (1987a). Adaptive variation in the mammalian respiratory system in relation to energetic demand: II. Reaching the limits to oxygen flow. Respiration Physiology. 69: 7-26. 
Taylor, C.R., E.R. Weibel, R.H. Karas, H. Hoppeler (1987b). Adaptive variation in the mammalian respiratory system in relation to energetic demand: VIII. Structural and functional design principles determining the limits to oxidative metabolism. Respiration Physiology. 69: 117-127.

Walsberg, G.E., M.S. Lea, S.S. Hillman (1986). Individual variation in maximum aerobic capacity: cardiovascular and enzymatic correlates in Rana catesbeiana. Journal of Experimental Zoology. 239: $1-5$.

Weibel, E.R. (1979). Oxygen demand and the size of respiratory structures in mammals. In: Evolution of Respiratory Processes, edited by S.C. Wood and C. Lenfant. New York and Basel, M. Dekker, pp 289-346.

Weibel, E.R., C.R. Taylor, P. Gehr, H. Hoppeler, O. Mathieu, G.M.O. Maloiy (1981). Design of the mammalian respiratory system. IX. Functional and structural limits for oxygen flow. Respiration Physiology. 44: 151-164.

Wharton, D.C. and A. Tzagoloff (1967). Cytochrome oxidase from beef heart mitochondria. Methods in enzymology. 10: 245-250.

Wodtke, E. (1981). Temperature adaptation of biological membranes. Compensation of the molar activity of cytochrome coxidase in the mitochondrial energy-transducing membrane during thermal acclimation of the carp (Cyprinus carpio L.). Biochimica et Biophysica Acta. 640: 710-720.

Wodtke, E. (1978). Lipid adaptation in liver mitochondrial membranes of carp acclimated to different temperatures. Phospholipid composition, fatty acid pattern and cholesterol content. Biochimica et Biophysica Acta. 529: 280-291.

Wodtke, E. (1976). Discontinuities in the arrhenius plots of mitochondrial membrane bound enzyme systems from a poikilotherm: acclimation temperature of carp affects transition temperatures. Journal of Comparative Physiology. 110: 145-157.

Wodtke, E. (1974a). Properties of isolated mitochondria of the eel and their dependency on acclimation temperature with special regard to oxidative phosphorylation. Journal of Comparative Physiology. 91: 277-307. 
Wodtke, E. (1974b). Effects of acclimation temperature on the oxidative metabolism of the eel (Anguilla anguilla, L.). Journal of Comparative Physiology. 91: 309-332.

Wodtke, E. (1973). Effects of acclimation temperature on aerobic energy production in eel liver: oxidative phosphorylation in isolated mitochondria. In: Effects of Temperature on Ectothermic Organisms: Ecological Implications and Mechanisms of Compensation. W. Wieser, ed. Springer, Berlin. 


\section{APPENDIX}

\section{ASSAYS OF THE MITOCHONDRIAL ELECTRON TRANSPORT SYSTEM}

\section{STOCK SOLUTIONS}

1) $0.25 \mathrm{M}$ Potassium phosphate buffer $(\mathrm{pH}=7.4)$. Monobasic potassium phosphate $\left(\mathrm{KH}_{2} \mathrm{PO}_{4}\right) \mathrm{MW}=136.09$, dissolve $3.4 \mathrm{~g}$ in $80 \mathrm{ml}$ double distilled water $\left(\mathrm{ddH}_{2} \mathrm{O}\right)$ and adjust $\mathrm{pH}$ to 7.4 with $5 \mathrm{~N} \mathrm{KOH}$. Dilute to $100 \mathrm{ml}$ final volume with $\mathrm{dd} \mathrm{H}_{2} \mathrm{O}$. May be stored refrigerated for 1 month.

2) $0.5 \mathrm{M}$ Phosphate $/ 5 \%$ Tween 80 buffer (10x P $/ \mathrm{T}$ buffer). Dissolve $6.8 \mathrm{~g} \mathrm{KH}_{2} \mathrm{PO}_{4}$ in $80 \mathrm{ml} \mathrm{ddH}_{2} \mathrm{O}$, add $5 \mathrm{ml}$ Tween 80 and stir until detergent dissolves. Adjust $\mathrm{pH}$ to 7.4 with $5 \mathrm{~N} \mathrm{KOH}$ and dilute to $100 \mathrm{ml}$ final volume with $\mathrm{dd} \mathrm{H}_{2} \mathrm{O}$. May be stored refrigerated for 1 month.

3) $1 \times$ Phosphate/Tween buffer (P/T buffer), $\mathrm{pH}$ 7.0. Dilute $10 \mathrm{ml}$ $10 \times \mathrm{P} / \mathrm{T}$ buffer with $70 \mathrm{ml} \mathrm{ddH} 2 \mathrm{O}$ and adjust $\mathrm{pH}$ to 7.0 with $1 \mathrm{~N} \mathrm{HCl}$. Dilute to $100 \mathrm{ml}$ final volume with $\mathrm{ddH}_{2} \mathrm{O}$. May be stored refrigerated for not more than one month. 
4) $0.05 \mathrm{M}$ Magnesium Chloride $\left(\mathrm{MgCl}_{2}\right)$. $\mathrm{MgCl}_{2}$ hexahydrate $\mathrm{mw}=203.33$. Dissolve $1.02 \mathrm{~g}$ into $100 \mathrm{ml}$ final volume $\mathrm{ddH}_{2} \mathrm{O}$. May be stored refrigerated for 1 month.

5) $0.2 \mathrm{M}$ Potassium cyanide ( $\mathrm{pH} 7.4$ ). $\mathrm{KCN} \mathrm{mw}=65.12$. Dissolve $0.13 \mathrm{~g}$ into $5 \mathrm{ml}$ ice cold $\mathrm{ddH}_{2} \mathrm{O}$ in an ice bath in a fume hood. Adjust $\mathrm{pH}$ to 7.4 with ice cold $1 \mathrm{~N} \mathrm{HCl}$ (about $1.5 \mathrm{ml}$ ) using narrow range $\mathrm{pH}$ paper.

Dilute to $10 \mathrm{ml}$ final volume with ddH2O, cover tightly and keep on ice or under refrigeration until used. Make fresh daily.

6) 1.0M Succinate ( $\mathrm{pH} 7.4$ ). Succinic acid $\mathrm{mw}=118.1$. Dissolve $1.18 \mathrm{~g}$ in $7 \mathrm{ml} \mathrm{ddH_{2 }} \mathrm{O}$ and adjust $\mathrm{pH}$ to 7.4 with $5 \mathrm{~N} \mathrm{KOH}$. Dilute to $10 \mathrm{ml}$ final volume with $\mathrm{dd}_{2} \mathrm{O}$. One $\mathrm{ml}$ aliquots may be stored at $-70 \cdot \mathrm{C}$ for up to one year.

7) $1 \mathrm{mM}$ Ferrocytochrome c, mw=12,384. A P6DG ( BioRad polyacrylamide) desalting column $(0.7 \times 20 \mathrm{~cm})$ is equilibrated with $50 \mathrm{mM}$ phosphate buffer ( $\mathrm{pH} 7.0$ ). $25 \mathrm{mg}$ cytochrome c (Sigma horse heart type IV) is dissolved in $1 \mathrm{ml} 50 \mathrm{mM}$ phosphate buffer and reduced by addition of $50 \mu \mathrm{l} 0.5 \mathrm{M}$ ascorbate with $1 \mathrm{mM}$ EDTA (pH5). The reduced " $c$ " solution is then added to the P6DG column and eluted with $50 \mathrm{mM}$ phosphate buffer ( $\mathrm{pH} 7)$. The dark red band is collected and the dilute tail left on the column. The concentration of 
ferrocytochrome $\mathrm{c}$ is determined as described below and diluted, if necessary, to $1 \mathrm{mM}$ with phosphate buffer. Aliquots of $0.2 \mathrm{ml}$ may be stored frozen at $-70 \cdot \mathrm{C}$ for up to one year.

8) $1 \mathrm{mM}$ Ferricytochrome $\mathrm{c}, \mathrm{mw}=12,384$. Dissolve $13 \mathrm{mg}$ into $1 \mathrm{ml}$ $50 \mathrm{mM}$ phosphate buffer ( $\mathrm{pH} 7.4)$. Make fresh daily.

9) $2 \mathrm{mg} / \mathrm{ml}$ Rotenone (approximately $5 \mathrm{mM}$ ). $\mathrm{mw}=394.1$. Dissolve $10 \mathrm{mg}$ in $5 \mathrm{ml} \mathrm{100 \%} \mathrm{ethanol} \mathrm{in} \mathrm{brown} \mathrm{glass,} \mathrm{stir} \mathrm{until} \mathrm{dissolved.}$

Rotenone is extremely light sensitive and should be stored, weighed and prepared in subdued light and brown glass. Make rotenone solutions fresh daily.

10) $2 \mathrm{mM}$ 2,6-Dichlorophenol indophenol (DCIP) $\mathrm{mw}=2$ 291.0. Dissolve $5.8 \mathrm{mg}$ into $10 \mathrm{ml}$ final volume with $\mathrm{ddH}_{2} \mathrm{O}$. Make fresh daily and store in brown glass.

11) $40 \mathrm{mM}$ Phenazine methosulfate (PMS) $\mathrm{mw}=310$. Protect from light during weighing, pipetting, and at all times. Dissolve $12.4 \mathrm{mg}$ into $1 \mathrm{ml} \mathrm{ddH} \mathrm{H}_{2} \mathrm{O}$. This solution is extremely light sensitive: make fresh daily and store in brown glass. 
12) $1 \mathrm{mM}$ Potassium ferricyanide $\mathrm{K}_{3} \mathrm{Fe}(\mathrm{CN})_{6} \mathrm{mw}=329$.6. Dissolve $33 \mathrm{mg}$ into $100 \mathrm{ml}$ final volume $\mathrm{ddH}_{2} \mathrm{O}$. Make fresh daily. 


\section{NADH OXIDASE}

This assay follow the oxidation of NADH at $340 \mathrm{~nm}$ by Complexes I,III, and IV (NADH:Oxidase) of the electron transport system.

A working buffer is made, fresh daily, from the following (20 assays):

Solution

Amount

Final Concentration

1) $0.25 \mathrm{M}$ Phosphate buffer(pH 7) $1 \mathrm{ml}$

$25 \mathrm{mM}$

2) $0.05 \mathrm{M} \mathrm{MgCl}_{2}$

$1 \mathrm{ml}$

$5 \mathrm{mM}$

3) $1 \mathrm{mM}$ Ferricytochrome

$0.1 \mathrm{ml}$

$10 \mu \mathrm{M}$

4) $\mathrm{NADH}$

$1.6 \mathrm{mg}$

$0.2 \mathrm{mM}$

5) BSA

$25 \mathrm{mg}$

$2.5 \mathrm{mg} / \mathrm{ml}$

6) $\mathrm{ddH}_{2} \mathrm{O}$

$\underline{7.4 \mathrm{ml}}$

Final Volume

$9.5 \mathrm{ml}$

To a $1.5 \mathrm{ml}$ Eppendorf tube add:

7) $475 \mu$ l Working buffer

8) $25 \mu$ l Mitochondrial suspension 
Sonicate in ice bath $3 \times 15$ seconds at setting 1 (about 30 watts on a Branson128 sonicator). Place sonicated sample in a prewarmed $0.6 \mathrm{ml}$ cuvette and measure change in OD 340 . Add $1 \mu$ rotenone solution to the sample after $2 \mathrm{~min}$ and read for another $3 \mathrm{~min}$. This activity in the presence of rotenone is subtracted from the total activity to determine the electron transport chain activity.

Calculations: The NADH:Oxidase assay measures the decrease in absorbance of $N A D H$ at $340 \mathrm{~nm}$. A line is drawn through the steepest linear part of the trace ( the rate is usually linear for more than three minutes) and the initial and final absorbance are measured, the difference in initial minus final absorbance $=\Delta \mathrm{A}$. The calculation of specific activity is as follows:

$$
\Delta \mathrm{A} /(6.22 \times 5 \times 0.05)=\text { specific activity }(\mu \mathrm{M} / \mathrm{min} / \mathrm{mg}) \text {, }
$$

where 6.22 is the millimolar extinction coefficient for NADH.

REFERENCE: Fischer, et. al. (1986) 


\section{SUCCINATE CYTOCHROME C REDUCTASE AND SUCCINATE DEHYDROGENASE}

These assays measure the activity of Electron Transport Complexes II and III by following the reduction of ferricytochrome $\mathrm{C}$ or dichlorophenol-indophenol (DCIP) by succinate. The Succinate Dehydrogenase (SDH) assay measures the activity of the two subunits of Complex II comprising SDH using the artificial electron acceptor phenazine methosulfate (PMS) as primary electron acceptor, then donating electrons to DCIP. Substitution of ferricytochrome $\mathrm{c}$ for PMS and DCIP and reading absorbance at $550 \mathrm{~nm}$ gives a measure of the combined activity of Complexes II and III (Succinate: Cytochrome c reductase).

An assay buffer is made, fresh daily, of the following (20 assays):

Solution

Amount Final Concentration

1) $0.25 \mathrm{M}$ Phosphate buffer $(\mathrm{pH} \mathrm{7.4)} 2 \mathrm{ml} \quad 50 \mathrm{mM}$

2) $1.0 \mathrm{M}$ Succinate $(\mathrm{pH} 7.4) \quad 0.2 \mathrm{ml} \quad 20 \mathrm{mM}$

3) $0.2 \mathrm{mM} \mathrm{KCN}(\mathrm{pH} 7.4)$

$0.1 \mathrm{ml} \quad 2 \mathrm{mM}$

4) $2 \mathrm{mg} / \mathrm{ml}$ Rotenone

$10 \mu 1$

$2 \mu \mathrm{g} / \mathrm{ml}$ 
5) $\mathrm{dd}_{2} \mathrm{O} \quad 6.99 \mathrm{ml}$

Final Volume $9.30 \mathrm{ml}$

Pre-incubation: (to activate samples prior to assay)

The following is incubated in a $30^{\circ}$ water bath for 30 minutes:

6)10x Phosphate/Tween

7) 1.0M Succinate

8) Diluted mitochondria 1:20*

9) $\mathrm{ddH}_{2} \mathrm{O}$

Final volume
$10 \mu l$

$2 \mu l$

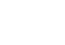

$50 \mathrm{mM} / 0.5 \%$

$20 \mathrm{mM}$

$50 \mu l$

$\underline{38 \mu 1}$

$100 \mu 1$

After incubation keep on ice until used.

* A $10 \mu$ laliquot of concentrated mitochondria is diluted to $200 \mu l$ with SET with $0.1 \%$ Tween 80 (1:20).

SET $=250 \mathrm{mM}$ Sucrose, $10 \mathrm{mM}$ Tris $\mathrm{HCl}, 2 \mathrm{mM}$ EDTA, $0.1 \%$ Tween $80, \mathrm{pH} 7.4$.

\section{Assay Procedure:}

To a $0.6 \mathrm{ml}$ cuvette add:

1) $465 \mu$ l Assay Buffer 
2) $10 \mu$ l activated mitochondria ( final Tween concentration $=0.01 \%$ )

Place cuvette in spectrophotometer and allow 2 minutes to warm to $30^{\circ}$.

For SDH: Add $12.5 \mu$ leach of $40 \mathrm{mM}$ PMS and $2 \mathrm{mM} \mathrm{DCIP}$ and mix as above. Record decrease $O_{600}$ for $3 \mathrm{~min}$. The final concentration of PMS is $1 \mathrm{mM}$, the final concentration of DCIP is $50 \mu \mathrm{M}$.

For Succinate: cytochrome c reductase: Add $25 \mu$ ferricytochrome c, mix well by inverting $3 x$ and replace in the spec. Record increase $\mathrm{OD}_{550}$ for $3 \mathrm{~min}$. The final concentration of ferricytochrome $\mathrm{c}$ is $50 \mu \mathrm{M}$.

The millimolar extinction coefficient for reduced cytochrome $c$ at $550 \mathrm{~nm}$ is 27.6. Specific activity is determined as follows:

$$
\Delta \mathrm{A}(27.6 \times 3 \mathrm{~min} \times \text { [protein]mg) }
$$

The millimolar extinction coefficient for reduced DCIP at $600 \mathrm{~nm}$ is 19.1. Specific activity is calculated as follows:

$$
\Delta \mathbf{A}(19.1 \times 3 \mathrm{~min} \times \text { [protein]mg })
$$

REFERENCES: Fischer, et. al. (1985), Singer, T.P. (1974) 


\section{CYTOCHROME C OXIDASE}

This assay follows the oxidation of ferrocytochrome $c$ by cytochrome oxidase by following the decrease in $\mathrm{OD}_{550}$.

\section{Solutions:}

1) $50 \mathrm{mM}$ Phosphate/0.5\% Tween buffer, $\mathrm{pH} 7.0$

2) $1 \mathrm{mM}$ Ferrocytochrome $\mathrm{c}$

3) Diluted mitochondria (1:20 in SET/0.1\% Tween 80)

4) $1 \mathrm{mM}$ Potassium ferricyanide

\section{Determination of [ferrocytochrome c]:}

Because the rate of reaction is directly dependent upon the concentration of ferrocytochrome $c$, an assay of the stock solution is conducted just prior to the COX assay.

To a $0.6 \mathrm{ml}$ cuvette add:

5) $495 \mu$ l Phosphate/Tween buffer

6) $5 \mu$ l ferrocytochrome $c$ stock
a) read $\mathrm{OD}_{550}$
b) add a small grain of sodium dithionite and mix well
c) read $\mathrm{OD}_{550}$ ( absorbance of $100 \%$ reduced solution). 
d) divide (a) by (c) to determine the percent reduced

ferrocytochrome $\mathrm{c}$ in the stock solution. The solution should be greater than $90 \%$ reduced or discarded. The concentration of ferrocytochrome $c$ in the stock solution may be determined by dividing the absorbance (a) by 0.276 , this yields the concentration of ferrocytochrome $c(\mu \mathrm{M})$.

Cytochrome c Oxidase Assay

To a $0.6 \mathrm{ml}$ cuvette add:

7) $485 \mu$ l $1 \times$ Phosphate/Tween buffer

8) $10 \mu \mathrm{l}$ Mitochondrial suspension

Place in spectrophotometer and allow 5 min incubation at $30^{\circ} \mathrm{C}$.

9) Quickly add $5 \mu$ l reduced c, immediately start spectrophotometer or stopwatch, mix cuvette by inverting $3 x$ and replace in spec.

This sequence is essential to determine the initial rate of cytochrome oxidase activity.

10) Record decrease $O_{550}$ for 5 minutes, accumulating at least 10 data points ( 30 second intervals). Then add $1 \mu$ ferricyanide, allow $1 \mathrm{~min}$ for sample to react and record the fully oxidized 
$\mathrm{OD}_{550}$. This oxidized value is subtracted from all previous data points.

The spectrophotometric assay of Cytochrome c Oxidase follows first order reaction kinetics which are directly proportional to the initial concentration of ferrocytochrome $\mathrm{c}$. It is essential that the initial concentration of ferrocytochrome $\mathrm{c}$ remain constant for all assays. The rate falls off as an exponential function of [ferrocytochrome c] which is described by the equation:

$$
v_{t}=v_{0} e^{-k t}
$$

To calculate Cytochrome Oxidase activity:

1) Plot the data points on semi-log graph paper and determine the slope.

a) Rate constant $(k)=$ slope $\times 2.303$ (this converts from $\log _{10}$ to e).

b) Initial velocity $\left(v_{0}\right)=k \times$ [ferrocytochrome c] ; the units are $\mathrm{nmol} / \mathrm{ml} / \mathrm{min}$.

c) Specific activity $=\mathrm{v}_{\mathrm{O}} /$ [mitochondrial protein per $\mathrm{ml}$ assay]; the units are $\mathrm{nmol} / \mathrm{min} / \mathrm{mg}$.

2) Alternatively, $k$ can be determined by calculating the half time $\left(t_{1 / 2}\right)$ of the reaction: $k=0.693 /\left(t_{1 / 2}\right)$. 
3) A third alternative is to calculate $k$ by means of an exponential curve fitting program .

Note: This assay is optimal at $10 \mu \mathrm{g} / \mathrm{ml}$ human mitochondrial protein and $1 \mu \mathrm{g} / \mathrm{ml}$ for beef heart and muscle. Care must be taken to ensure that the reaction does not proceed too rapidly or accuracy is reduced. The optimal value for $k$ is between 0.2 and 0.5 , and the concentration of protein should be adjusted, by diluting sample, to give an activity within this range.

REFERENCES: Wharton, D.C.and A.Tzagoloff (1967), Darley-Usmar, V.M., N.G. Kennaway, N.R.M. Buist, R.A. Capaldi (1983). 